\title{
Relating plankton assemblages to environmental variables using instruments towed by ships-of- opportunity
}

\author{
J. A. Lindley, R. Williams \\ Plymouth Marine Laboratory, Prospect Place, Plymouth PL1 3DH, United Kingdom
}

\begin{abstract}
Undulating Oceanographic Recorders (UORs) and Continuous Plankton Recorders (CPRs) equipped with a suite of sensors were towed by merchant vessels in the North Sea between 1988 and 1991, recording a range of environmental variables. These were used to interpret the results of analyses of the plankton taken on CPR tows off the northeast coast of the UK in 1989 and in the Skagerrak and Kattegat in July 1988 and through 1989. Correlations were found between the biota and the environmental variables. The tidal front off the northeast coast of the UK and the front between the low salinity water in the Kattegat and the higher salinity water in the Skagerrak were dominant factors correlating with the distribution of the plankton assemblages. Discontinuities, defining the positions of the fronts, in the values of physical variables (temperature and, where measured, salinity and turbidity) were closely identified with geographical divisions between plankton assemblages. Measures of irradiance were found to be important on several occasions, presumably due to diel migrations of the zooplankton.
\end{abstract}

KEY WORDS: Plankton - Environment - Instrumentation $\cdot$ North Sea $\cdot$ Skagerrak $\cdot$ Kattegat

\section{INTRODUCTION}

Continuous Plankton Recorders (CPRs) have been towed by ships-of-opportunity to study variations in the distributions and abundance of the plankton for over 60 yr (Colebrook et al. 1991) with unbroken time series of data from 1947 to the present from the North Sea. Undulating Oceanographic Recorders (UORs) have been deployed from ships-of-opportunity intermittently since 1979, recording environmental variables and plankton in deployments in the English Channel (Aiken 1981b) and environmental variables only during deployments in the western North Sea and between Iceland and Portugal during 1989 to 1991 (Williams \& Aiken 1990)

Environmental variables have been measured on some CPR tows since 1965. Mechanical thermographs were installed on CPRs deployed on selected routes in the North Sea from 1965 and from 1974 these were succeeded by electronic instrumentation logging on miniature analogue tape recorders (Aiken 1980). The development of a suite of sensors (e.g. Aiken 1981b, Aiken \& Bellan 1986) and solid state data loggers resulted in a robust instrument package (now marketed by Chelsea Instruments as Aquapack ${ }^{\mathrm{TM}}$ ) which has been deployed from an Ocean Weather Ship in 1987 (Pattiaratchi et al. 1989) and on selected routes in the North Sea since 1987 (Williams \& Aiken 1990). Similar instrumentation in Undulating Oceanographic Recorders (UORs) (Aiken 1981a) was deployed on a route off the northeast coast of the UK from late winter to autumn of $3 \mathrm{yr}, 1989$ to 1991

The data generated by the CPR survey have been used to define geographical groupings of plankton taxa and groups of species with similar patterns of seasonal or interannual variations in abundance. Colebrook et al. (1961) and Colebrook (1964, 1972) derived groups of species or higher taxa classified according to their long-term mean distributions using $1^{\circ}$ latitude $\times$ $2^{\circ}$ longitude rectangles as the basic geographical unit. Colebrook $(1964,1984,1991)$ grouped species according to their mean seasonal cycles of occurrence over 
large areas. Reid et al. (1983), Robinson et al. (1986) and Williams et al. (1993) have used areas smaller than the $2^{\circ} \times 1^{\circ}$ rectangles to describe the distributions and seasonal cycles within restricted sub-areas of the CPR survey area. Distributions of individual species along single CPR tows were described in many early papers on the CPR survey (e.g. Lucas 1942, Rae \& Rees 1947) and in descriptions of exceptional events in restricted areas (e.g. Robinson 1968, Lindley et al. 1990). The present paper demonstrates the analysis by cluster analysis and multi-dimensional scaling of assemblages of co-occurring taxa along single CPR tows traversing frontal areas through a seasonal cycle and relating the distributions to the data from the data loggers in instrumented CPRs and UORs by application of recently developed techniques.

Plankton records were successfully taken with CPRs, usually with instrumentation, on the route between Grimsby and Aberdeen, UK, (LR route, see Fig. 1) in $11 \mathrm{mo}$ of the year 1989. UORs were towed on 8 occasions between March and October of the same year. The simultaneous collection of plankton samples and physical data has provided an opportunity to analyse assemblages in the plankton over a seasonal cycle in relation to environmental variables. This route crosses the tidal front, between permanently mixed water to the south and seasonally thermally stratified water to the north, off Flamborough Head, NE England (see Pingree \& Griffiths 1978). At the northern end of this route the waters near the Scottish coast are transitional

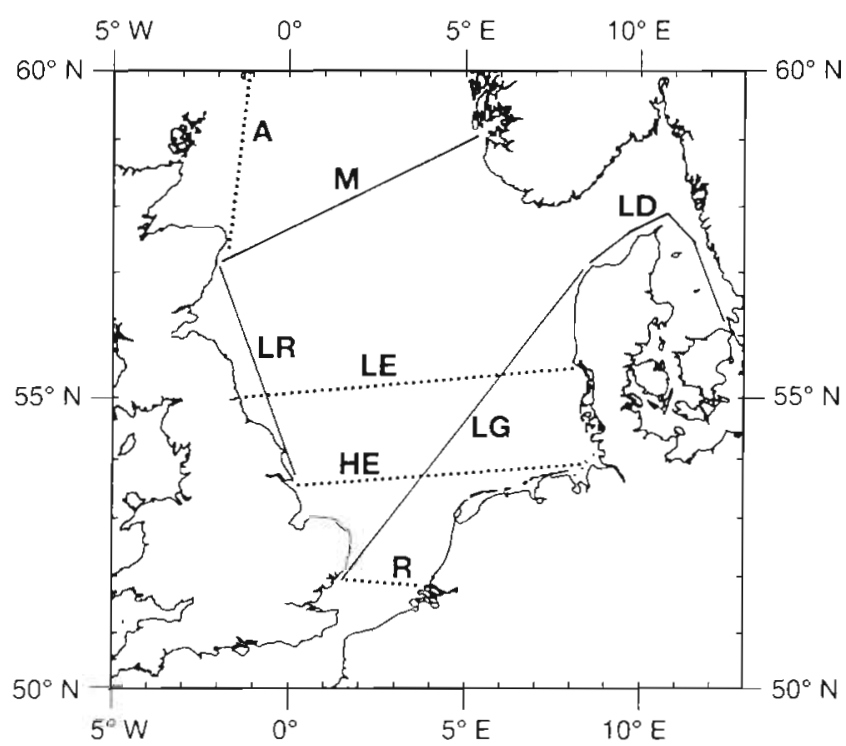

Fig. 1. Standard routes of the CPR survey in the North Sea in 1989. Continuous lines indicate routes on which instrumented CPRs were deployed (i.e. environmental variables were measured on the same tow). Dotted lines indicate routes where CPRs sampled plankton only. UORs were towed on the LR route between mixed and seasonally thermally stratified (Williams \& Lindley in press). A contrasting route on which instrumented CPRs were deployed passed through a front between low salinity water in the Kattegat and higher salinity water in the Skagerrak (the LD route, see Fig. 1). The Kattegat waters near the Swedish coast have suffered from eutrophication attributed to increasing nutrient supply (Andersson \& Rydberg 1993). This route was sampled from January to May and in October and November 1989 and data from a tow in July 1988 was analysed as well to represent summer conditions. The front is evident here throughout the year but is variable in position (Richardson 1985) whereas the Flamborough front is only detectable during that part of the year when the waters are thermally stratified.

\section{METHODS}

Continuous Plankton Recorders (CPRs) (Edinburgh Oceanographic Laboratory 1973) are towed by merchant vessels and Ocean Weather Ships on standard routes at an average depth of $6.7 \pm 1.7 \mathrm{~m}$ (Hays \& Warner 1993). The towing speeds on the routes for which data are presented here were usually about 7.0 to $9.0 \mathrm{~m} \mathrm{~s}^{-1}$ ( 14 to $\left.17 \mathrm{knots}\right)$. The plankton is collected on a moving band of silk gauze with mesh aperture size of about $285 \times 315 \mu \mathrm{m}$ which is divided into sections representing the plankton retained from $3 \mathrm{~m}^{3}$ of water during $16 \mathrm{~km}$ of tow. The plankton are analysed as described by Rae (1952) and Colebrook (1960). Usually only alternate blocks are analysed. The standard routes in operation in the North Sea during 1989 are shown in Fig. 1.

Undulating Oceanographic Recorders (UORs) are also towed by ships-of-opportunity. Whereas the CPRs are dispatched to the towing vessels by commercial road transport and are towed unaccompanied by scientific staff, the deployment of UORs was supervised by a member of the Plymouth Marine Laboratory staff. On the LR route (Fig. 1) undulation between 3 and $23 \mathrm{~m}$ depth in each $1.6 \mathrm{~km}$ of tow provided data on the vertical distribution of environmental variables along the tow track. The deployment of the UOR on the southern part of the route was restricted by shallow water so deployment was limited to areas north of $53^{\circ} 50^{\prime}$ to $54^{\circ} 00^{\prime} \mathrm{N}$ whereas the CPRs were usually deployed from $53^{\circ} 38^{\prime} \mathrm{N}$. The UORs were towed on this route from March to October in 1989 and 1990 and from February to August 1991

The instrumentation for recording environmental variables during tows of the CPRs in 1989 consisted of sensors for depth, temperature, conductivity, chlorophyll fluorescence and downwelling and upwelling 
irradiance at $450 \mu \mathrm{m}$ (blue) and $550 \mu \mathrm{m}$ (green). The UORs also had instruments for recording turbidity and upwelling and downwelling radiation at $410 \mu \mathrm{m}$ (violet). Not all the sensors were in used on all tows. Data used for analyses in conjunction with the plankton results are listed with the results of the analyses in Table 4 . For most of the tows with the CPR, data were lagged at 30 s intervals, while $12 \mathrm{~s}$ or $6 \mathrm{~s}$ intervals were used with the UOR. Williams \& Aiken (1990) give further information on the deployment on UORs and instrumented CPRs during 1989. During 1989 the fluorometers for measuring chlorophyll concentration were calibrated using acetone extracts of chlorophyll, not in vivo material.

Data for both phytoplankton and zooplankton were included in the analysis of plankton data. The 'accepted values' (Colebrook 1960) of the total numbers per sample of zooplankton taxa were used. Due to the mesh aperture of the sampling gauze, sampling of phytoplankton taxa by the CPR gives only a measure of relative variations of abundance within taxa. This, combined with the very small sub-sample size for phytoplankton, would result in the more quantitative zooplankton sampling being given less weight than the phytoplankton data if total numbers per sample of the latter were used. To incorporate the phytoplankton into the analysis the 'accepted value' for the numbers of cells seen in the sub-sample was used. In the case of both the phytoplankton and the zooplankton, taxa which occurred in only small numbers ( 1 to 3 observed in relevant stage of analysis) in single or few scattered samples were excluded.

The analysis of the plankton data followed the procedure described by Field et al. (1982). Matrices of Bray-Curtis coefficients were calculated for the similarities between the taxa occurring within samples and the distributions of taxa between samples for each tow. A dendrogram and a 2-dimensional scatter plot were derived from each matrix, the former by nearestneighbour clustering method and the latter by nonmetric multi-dimensional scaling (MDS). Groupings of samples and of taxa which could be identified from both the dendrogram and the scatter plot were interpreted as indicating areas with different plankton assemblages and the composition of different assemblages respectively. The reliability of the scatter plots was indicated by the stress coefficient (if the value is $<0.15$ then the 2-dimensional plot is a good representation of the relationships described). The taxa included in at least 1 analysis are listed in Table 1.

Where environmental variables were measured by instruments on the same CPR tow as the plankton data were collected ('instrumental CPRs'), the mean value of each recorded variable was calculated for each $16 \mathrm{~km}$ section of tow, corresponding to the plankton samples, using a program written by D. Adams (Plymouth Polytechnic, pers. comm.). Water depth and, on the LR route, the stratification parameter $\left(h / U^{3}\right.$, where $h=$ water depth in $\mathrm{cm}$ and $U=$ tidal stream velocity in $\mathrm{cm} \mathrm{s}^{-1}$; Pingree \& Griffiths 1978) at the mid-sample position were incorporated into the analysis in addition to the recorded data. The stratification parameter was not used on the LD route as stratification in the Kattegat is a permanent halocline, rather than a seasonal thermocline, developing in otherwise homogeneous conditions where depth and tidal stream velocity permit. On tows on the LR route where no instrumental data were available but a UOR tow took place within 2 wk of the CPR tow, the values of variables at the midsample latitude on the UOR tow were used. In addition to the values of variables at the CPR sampling depth the variability over the undulation depth range of the UOR was available.

The relationships between the plankton and the environmental data were analysed using the BIO-ENV program described by Clarke \& Ainsworth (1993). This uses rank dissimilarities between samples resulting from the analysis of the biota with equivalent values derived from the environmental data to calculate weighted Spearman rank correlation coefficients. Different combinations of environmental variables are tested and the combination which gives the highest correlation is taken as the group of variables that 'best explains' the biotic structure.

\section{RESULTS}

The data resulting from the deployment of UORs and instrumented CPRs off the northeast coast of the UK (LR route) in 1989 were summarised by Williams \& Aiken (1990). Examples of the data are shown in Fig. 2 which shows the temperature profiles from the UOR tows in April, June and September. The total variation in temperature over the tow in April was $<0.5^{\circ} \mathrm{C}$ with weak stratification over most of the route. The temperature difference between the surface and $21 \mathrm{~m}$ was 3 to $5{ }^{\circ} \mathrm{C}$ over much of the central part of the tow in June but there were smaller differences at the northern and southern ends of the tow. In September significant stratification was evident from the position of the front, near the southern end of the tow to about $56^{\circ} \mathrm{N}$. Fig. 3 shows the variables measured by the instrumented CPR tow in July. Comparison of this record with data from the UOR towed on 1 August showed that the abrupt change in temperature at about $2 \mathrm{~h}$ into the tow marked the position of the front between well-stratified water to the north and more mixed water to the south (see Lindley et al. 1993). The mixed water to the south of the front was also much more turbid than the 
Table 1. Planktonic taxa included in analyses of assemblages, the numbers used to identify species in the dendrograms and scatter plots in Fig. 8 (LR) and Fig. 14 (LD) and the abbreviated form used in Figs. 9 \& 15. 'Phytoplankton colour' is the assessment of green colouration of the filtering gauze (Robinson 1970)

\begin{tabular}{|c|c|c|c|}
\hline LR & LD & Taxa & Abbreviated form \\
\hline \multirow[t]{7}{*}{1} & 1 & Phytoplankton colour & Colour \\
\hline & & Skeletonema costatum & Skeletonema \\
\hline & 2 & Thalassiosira spp. & Thalassiosira \\
\hline & 3 & Coscinodiscus spp. & Coscinodiscus \\
\hline & & Rhizosolenia styliformis & R. styliformis \\
\hline & & Rhizosolenia hebetata & R. hebetata \\
\hline & & Rhizosolenia shrubsolei & R. shrubsolei \\
\hline \multirow[t]{5}{*}{2} & 4 & Rhizosolenia alata alata & R. alata \\
\hline & 5 & Chaetoceros (Hyalochaete) spp. & Hyalochaete \\
\hline & 6 & Chaetoceros (Phaeoceros) spp. & Phaeoceros \\
\hline & & Thalassionema nitzschiodes & Thalassionema \\
\hline & & Nitzschia seriata & N. seriata \\
\hline 3 & 7 & Ceratium fusus & Cer. fusus \\
\hline 4 & 8 & Ceratium furca & Cer. furca \\
\hline 5 & 9 & Ceratium lineatum & Cer. lineatum \\
\hline \multirow[t]{3}{*}{6} & 10 & Ceratium tripos & Cer. tripos \\
\hline & & Ceratium horridum & Cer horridum \\
\hline & 11 & Dinophysis spp. & Dinophysis \\
\hline \multirow[t]{5}{*}{7} & & Protoperidinium spp. & Peridinium \\
\hline & & Prorocentrum spp. & Prorocentrum \\
\hline & & Noctiluca pelagica & Noctiluca \\
\hline & 12 & Coscinodiscus wailesii & C. wailesii \\
\hline & 13 & Calanus spp. I-IV & Calanus I-IV \\
\hline \multirow[t]{2}{*}{8} & 14 & $\begin{array}{l}\text { Paracalanus spp. \& Pseudo- } \\
\text { calanus spp. combined }\end{array}$ & Para-Pseudo \\
\hline & 15 & Temora longicornis & Temora \\
\hline \multirow[t]{3}{*}{9} & 16 & Acartia spp. & Acartia \\
\hline & & Centropages typicus & Cent typicus \\
\hline & 17 & Centropages hamatus & Cent hamatus \\
\hline 10 & & Copepod nauplii & Copepod nauplii \\
\hline \multirow[t]{2}{*}{11} & 18 & Oithona spp. & Oithona \\
\hline & 19 & Corycaeus anglicus & Corycaeus \\
\hline \multirow[t]{2}{*}{12} & & Total Copepods & Total Copepods \\
\hline & & Podon spp. & Podon \\
\hline \multirow[t]{7}{*}{13} & 20 & Evadne nordmanni & Evadne \\
\hline & 21 & Cirripedia larvae & Cirripedia \\
\hline & & Euphausiacea calyptopis & Calyptopis \\
\hline & 22 & Limacina retroversa & Limacina \\
\hline & & Chaetognatha $<8 \mathrm{~mm}$ & Chaetognatha $<8 \mathrm{~mm}$ \\
\hline & 23 & Bivalve larvae & Bivalve \\
\hline & 24 & Cyphonautes larvae & Cyphonautes \\
\hline 14 & 25 & Echinoderm larvae & Echinoderm \\
\hline 15 & & Appendicularia & Appendicularia \\
\hline 16 & 26 & Calanus finmarchicus V-VI & C. finmarchicus \\
\hline \multirow[t]{6}{*}{17} & 27 & Calanus helgolandicus V-VI & C. helgolandicus \\
\hline & & Metridia lucens & Metridia \\
\hline & 28 & Candacia armata & Candacia \\
\hline & 29 & Mysidacea & Mysid \\
\hline & & Gammaridea & Gammaridea \\
\hline & 30 & Hyperiidae & Hyperiid \\
\hline \multirow[t]{4}{*}{18} & 31 & Decapoda & Decapod \\
\hline & & Euphausiacea & Euphausiacea \\
\hline & & Chaetognatha $>8 \mathrm{~mm}$ & Chaetognatha $>8 \mathrm{~mm}$ \\
\hline & 32 & Fish larvae & Fish \\
\hline
\end{tabular}

water in the stratified area to the north (Fig. 4). The temperature data from the instrumented CPRs revealed well-defined changes in temperature at the approximate position of the front even in winter when the water is fully mixed on both sides of the front. The magnitude of these changes was, in many cases, small in comparison with the variation over the whole route. The position of these discontinuities could not be defined with certainty in temperature data averaged to correspond to the $16 \mathrm{~km}$ plankton samples (Fig. 5).

The dendrograms and MDS plots of the samples were used to group the samples containing similar plankton assemblages in each month. On the LR route geographically coherent groups of samples were identified in all months except January, June, November and December. Limited sampling in June (Newcastle to Aberdeen only) meant that this tow was not comparable to those in other months. In January, November and December the plankton was sparse and so the analyses of the data were weighted by more or less random accurrences. For the other months the most northerly sample and any samples grouped with it were arbitrarily defined

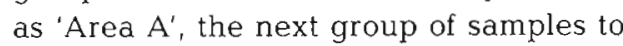
the south were called 'Area B' and so on Where the groups delineated in this way could be sub-divided then the sub-areas were indicated by appending 1 and 2 to the letter identifying the area to the most northerly and most southerly sub-areas respectively.

The mean positions of the 11 samples analysed on the LR route and the range of variation of these in 1989 are given in Fig. 6. An example of the dendrogram and MDS plot for July 1989 is shown in Fig. 7. The groupings of samples identified from the analyses are shown in Table 2 together with the stress coefficient from the 2-dimensional MDS scatter plot in each case. The results show that sample 21, south of the Flamborough front, was classified as separate from the rest of the samples in May, August, September and October. In March it was a sub-area associated with samples 7 to 17 and in April and July it was classified together with the most northerly samples: 

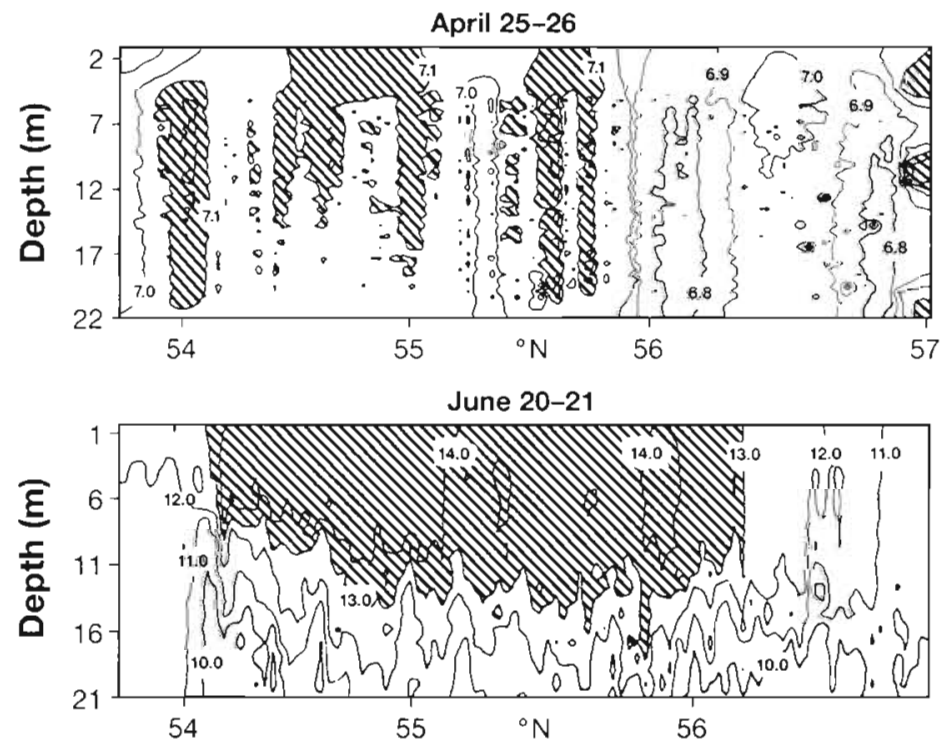

September $26-27$

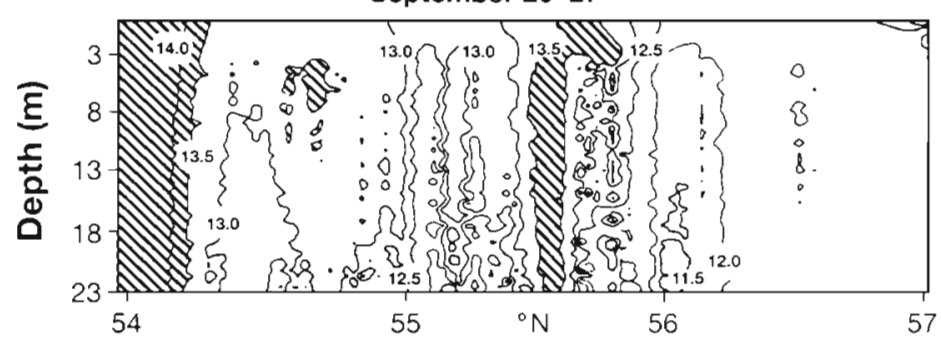

Fig. 2. Contour plots of temperature $\left({ }^{\circ} \mathrm{C}\right)$ on 3 tows of the UOR on the LR route (see Fig. 1). Contours at $0.1^{\circ} \mathrm{C}$ intervals in April, at $1.0^{\circ} \mathrm{C}$ intervals in June and $0.5^{\circ} \mathrm{C}$ intervals in September. The highest temperatures $\left(>7.1^{\circ} \mathrm{C}\right.$ in April, $>13.0^{\circ} \mathrm{C}$ in June and $>13.5^{\circ} \mathrm{C}$ in September) are shaded

1 and 3 in April and 1 only in July. Sample 19, off Flamborough Head, was classified as separate in March and April, as part of a group covering most of the central part of the tow from May to September and with samples 1 and 17 in October. Partitioning of the samples between 1 and 17 was variable but sample 1 and a varying number of samples grouped with it were always separate from the majority of the samples in the central part of the route.

The analyses of the plankton assemblages along the same route gave groups of differing size and composition from month to month. An example of a dendrogram and MDS scatter plot resulting from the analysis of the data for July is shown in Fig. 8.

In February plankton were sparse in the more northerly samples (Area A) which were taken by day but Calanus spp., Metridia lucens, euphausiids and hyperiids comprised an assemblage which occurred in the samples taken further south (Area B) at night. The distributions of the groups and their compositions in the other months where geographically coherent patterns were found are shown in Fig. 9. In every month the group which contained the most taxa was the most widespread, with the main area of abundance including the central, seasonally stratified waters classified as Area B. Few taxa were abundant in Area C in March (sample 19), September and October (sample 21) and Area A in May (samples 1 and 13) and September (samples 1 and 7). In April, when sample 21 was grouped with the Scottish coastal samples (1 and 3), members of a group including diatoms and copepods typically abundant at early stages of the seasonal cycle (Colebrook 1984) were numerous in these samples and sample 19 (Area C). A group including the diatom Rhizosolenia styliformis and dinoflagellates which are typically most abundant later in the seasonal cycle than the diatoms in Areas A and C (Robinson 1965, Colebrook 1984) occurred mainly in Area B1 in the same month. In July, when the 2 ends of the route were again classified together in the analysis, the dinoflagellates Ceratium lineatum and Peridinium spp. were abundant in samples 1 and 21. The former is mainly oceanic (Robinson 1961, 1965) and in the North Sea may be associated with the inflow of Atlantic water down the east coast of the UK. Adult Calanus spp. (copepodites V \& VI) occurred only in samples taken at night in that month and in May the larger zooplankton (Calanus spp. V \& VI, hyperiids, decapods, euphausiids, adult chaetognatha and fish larvae) occurred mainly at night. Later in the year the only assemblage which seemed related to night sampling was that comprising Temora longi-

Table 2. Continuous plankton recorder samples on the LR route (see Fig. 6) in 1989. Grouping of samples according to the results of cluster analysis and MDS ordination. The stress coefficients for the 2-dimensional MDS plot (stress) are listed. (For further details see text.) ns: not sampled

\begin{tabular}{|lcccccccccccc|}
\hline & 1 & 3 & 5 & 7 & 9 & 11 & 13 & 15 & 17 & 19 & 21 & Stress \\
\hline February & A & A & B & B & B & B & B & B & ns & ns & ns & 0.006 \\
March & A & A & A & B1 & B1 & B1 & B1 & B1 & B1 & C & B2 & 0.089 \\
April & A & A & B1 & B1 & B1 & B1 & B2 & B2 & B2 & C & A & 0.126 \\
May & A & B1 & B1 & B1 & B1 & B1 & A & B2 & B2 & B2 & C & 0.083 \\
July & A & B1 & B2 & B1 & B1 & B1 & B1 & B1 & B1 & B1 & A & 0.100 \\
August & A & A & A & A & B1 & B1 & B1 & B1 & B1 & B2 & C & 0.125 \\
September & A & B1 & B1 & A & B2 & B2 & ns & ns & B2 & B2 & C & 0.076 \\
October & A & B & B & B & B & B & B & B & A & A & C & 0.087 \\
\hline
\end{tabular}


Fig. 3. Results from instrumentation in a CPR towed on the $L R$ route (see Fig. 1) on 18 and 19 July 1989. The CPR was deployed at 17:45 h GMT; midnight was $375 \mathrm{~min}$ after the start of the record

July $1989 \quad$ LR route

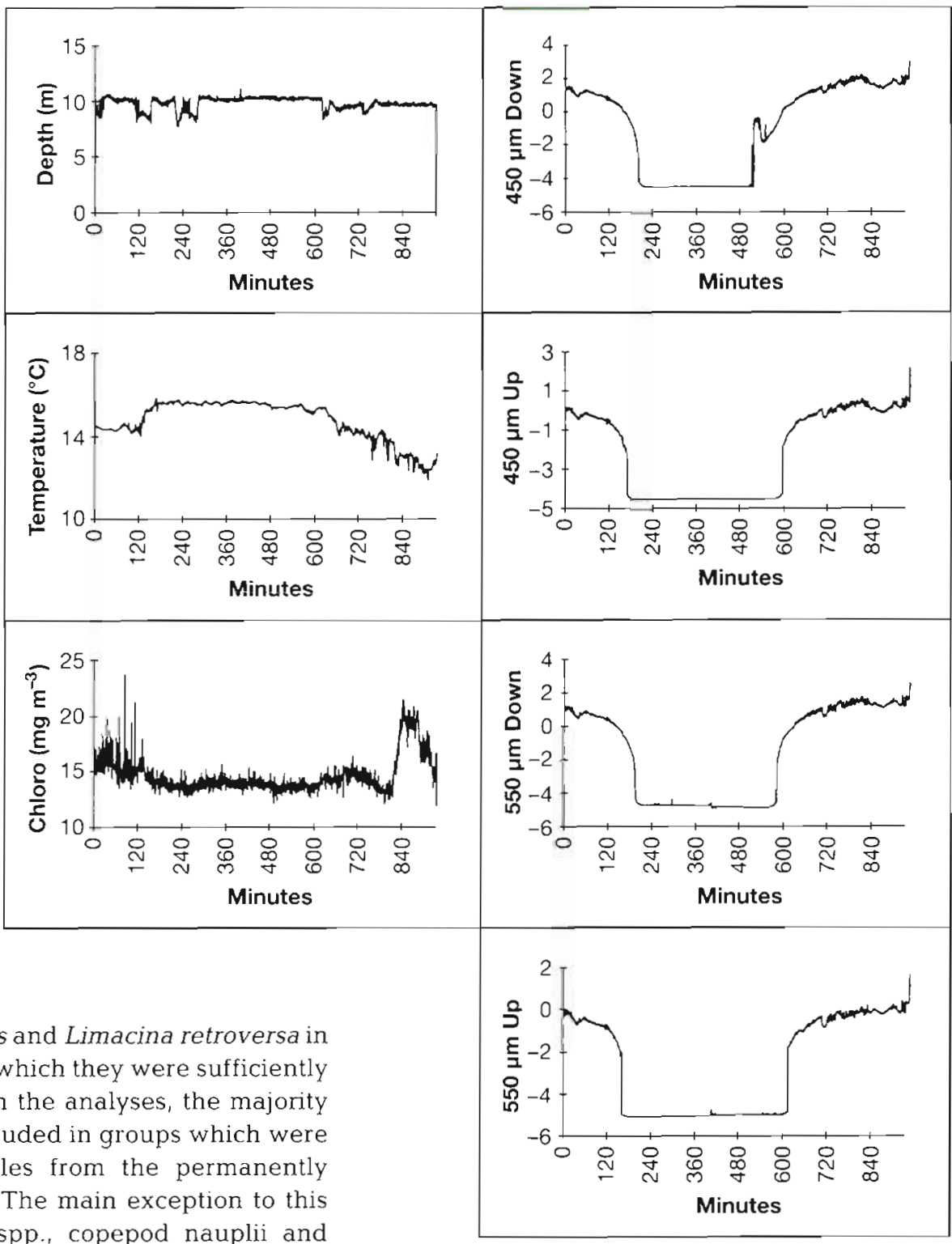

cornis, Centropages typicus and Limacina retroversa in August. In most months in which they were sufficiently abundant to be included in the analyses, the majority of dinoflagellates were included in groups which were occurred mainly in samples from the permanently stratified waters (Area B). The main exception to this was in August. Oithona spp., copepod nauplii and Evadne were usually included in the same groups as the majority of dinoflagellate taxa. Where Calanus finmarchicus and $C$. helgolandicus were referred to different groups, that containing $C$. finmarchicus had the more northerly distribution.

An example of a record from a data logger on tow on the LD route is that for October 1989 shown in Fig. 10. The salinity plot shows the sharp change in salinity at the front between the Baltic water in the Kattegat and the more saline water of the Skagerrak. The temperature also shows a discontinuity but this is less precisely defined than that in salinity. In the absence of salinity data for tows other than those in October and November 1989 the temperature data were used to define the position of the front on each tow (Fig. 11). As with the LR route the position of the front was less well defined, and in some cases it could not be identified from data giving the average values for the CPR plankton samples.

The grouping of samples to indicate areas containing similar plankton assemblages followed the procedure used for the LR route (see above). Where groups of samples occurred mainly in the Skagerrak they were defined as 'Area S' and groups mainly in the Kattegat were called 'Area $\mathrm{K}$ '. Samples which did not fall within these categories were called 'Area C' and 'Area D'. The positions of the 18 samples analysed in July 1988 are given in the upper chart in Fig. 12 and the mean positions and the variation in latitude and longitude of the samples analysed in 1989 are shown in the lower 
chart. As an example of the results of cluster analyses and MDS plots for data showing relationships between the samples from this route those from October 1989 are shown in Fig. 13.

In July 1988 the samples were divided into 2 coherent areas, samples 1 to 9 and samples 10 to 18 . The position of the front, as indicated by the change temperature, was in sample 10 . The groupings of samples in the tows taken in 1989 are shown in Table 3. In most months the division between the sample from Skagerrak and those from the Kattegat was well defined except perhaps in May 1989.

The plankton assemblages were defined by the results of the cluster and MDS analyses of the plankton data for each month. The dendrogram and scatter plot for October 1989 is given in Fig. 14 as an example of these analyses. In each case the assemblage with its main centre of abundance furthest to the west was called 'Group A' and those with their main areas of

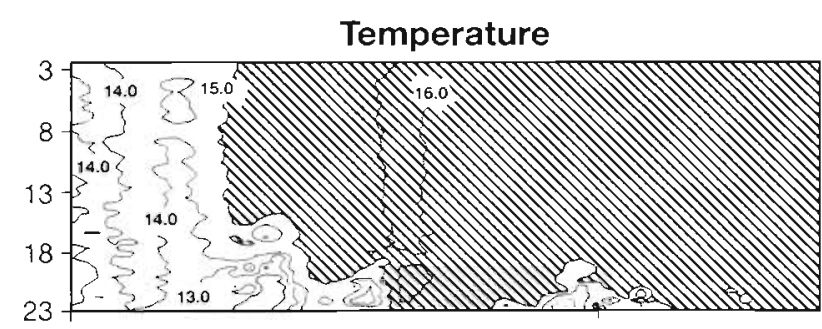

\section{Turbidity}

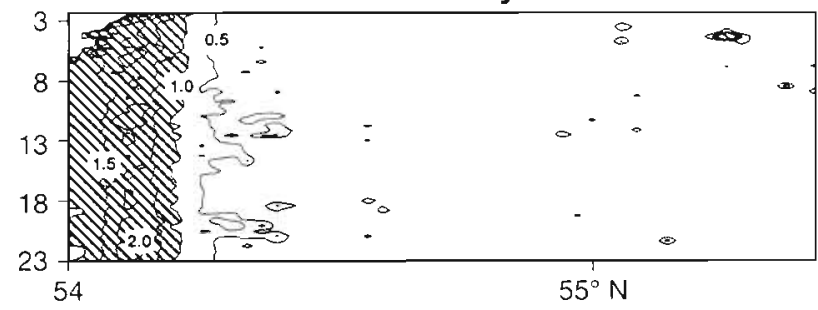

Fig. 4. Contour plots of temperature $\left({ }^{\circ} \mathrm{C}\right.$ ) and turbidity (parts per million) during an UOR tow on the LR route (see Fig. 1) on 1 and 2 August 1989
Fig. 5. Temperature $\left({ }^{\circ} \mathrm{C}\right)$ recorded during instrumented CPR tows on the LR route (see Fig. 1) during 1989. Left: original data; right: mean values per analysed plankton sample (for positions see Fig. 6). Arrows indicate the position of the Flamborough front

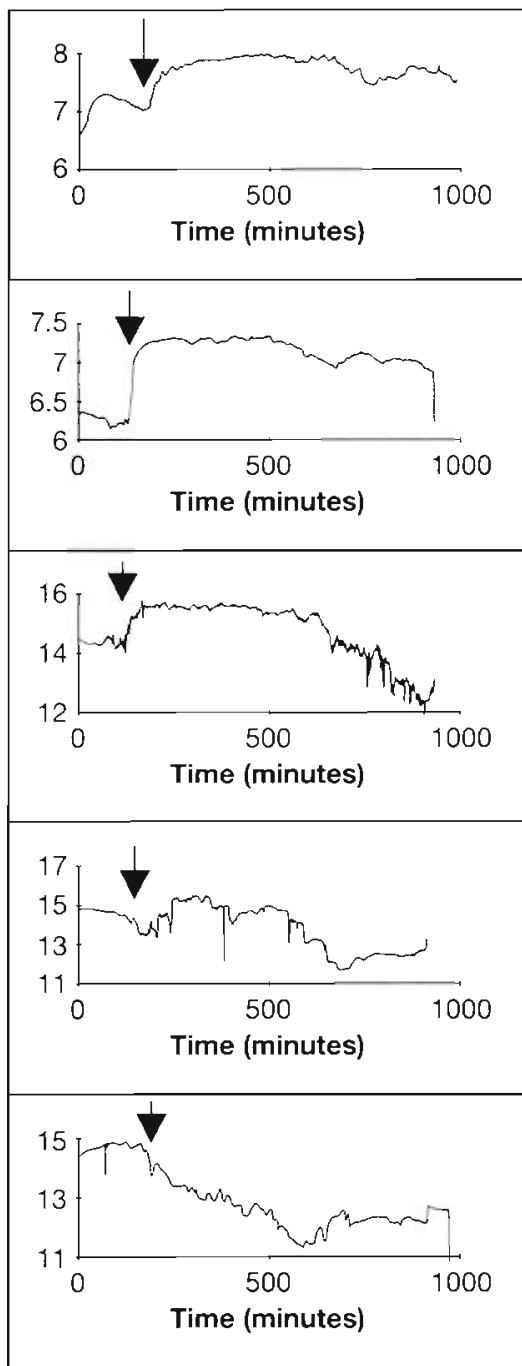




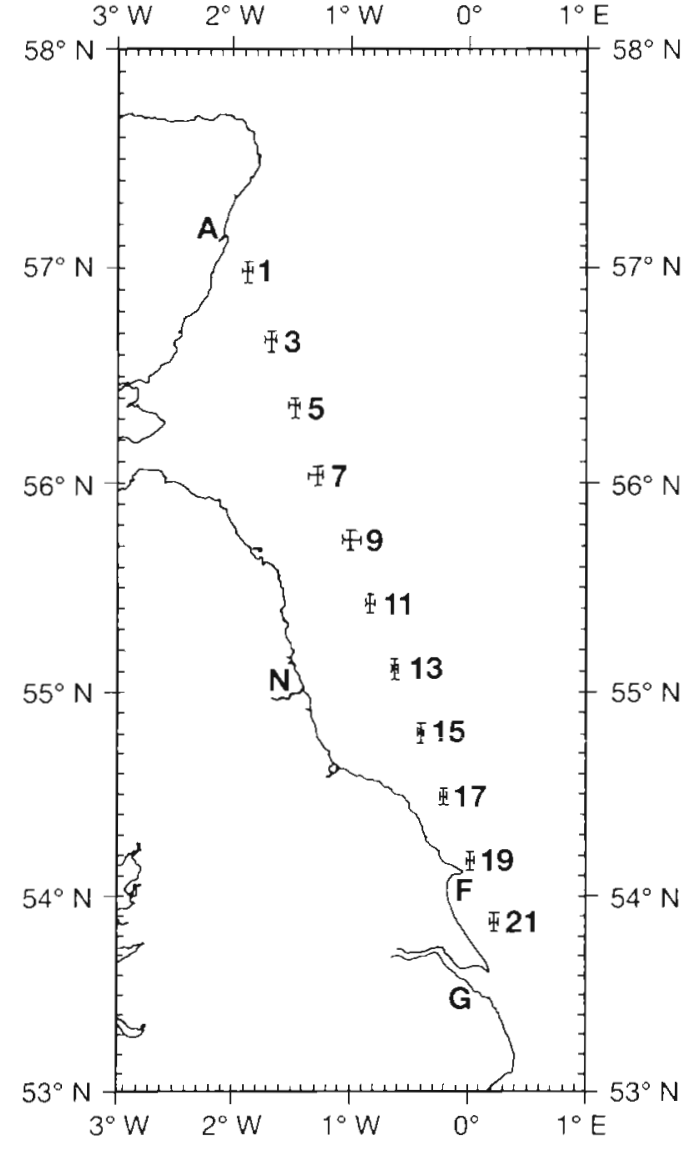

Fig. 6. Positions of analysed plankton samples on the LR route in 1989. The bars giving the range of latitude and longitude of the mid-points of the samples intersect at the mean position $\mathrm{A}=$ Aberdeen, $\mathrm{N}=$ Newcastle, $\mathrm{F}=$ Flamborough Head, $\mathrm{G}=$ Grimsby
Table 3. Continuous plankton recorder samples on the LD route (see Fig. 11) in 1989. Grouping of samples according to the results of cluster analysis and MDS ordination. The stress coefficients for the 2-dimensional MDS plot (stress) are listed. (For further details see text)

\begin{tabular}{|lcccccccccc|}
\hline & 1 & 3 & 5 & 7 & 9 & 11 & 13 & 15 & 17 & Stress \\
\hline January & S & K & S & S & S & K & K & K & K & 0.085 \\
February & S & S & K & S & S & C & K & K & K & 0.010 \\
March & C & S & C & S & S & S & K & K & K & 0.009 \\
April & C & D & S & S & S & K & K & K & K & 0.040 \\
May & S & S & C & K & K & S & C & K & K & 0.057 \\
October & S & S & S & S & S & K & K & K & K & 0.110 \\
November & S & S & S & S & C & K & K & K & K & 0.009 \\
\hline
\end{tabular}

abundance further east were ordered alphabetically from west to east. The results are shown in Fig. 15.

In July 1988, 4 groups were identified. Most taxa (Group C) were abundant throughout the route, hence the high level of similarity between the samples. Two groups (A and B) were abundant in the Skagerrak (samples 1 to 9) while 1 group of 3 phytoplankton taxa was most abundant in the Kattegat (samples 10 to 18).

Two groups were identified in each of the months for which data were analysed in 1989. In each month Group B was most abundant in the Kattegat and, except in April and May rare or absent in samples taken in the Skagerrak. Group A was more variable and usually more widespread. The spring diatom bloom was clear in the Kattegat in March 1989 when Group B consisted of 5 diatom taxa including Skeletonema costatum which is typically abundant early in the spring bloom (Colebrook 1984). In April diatoms
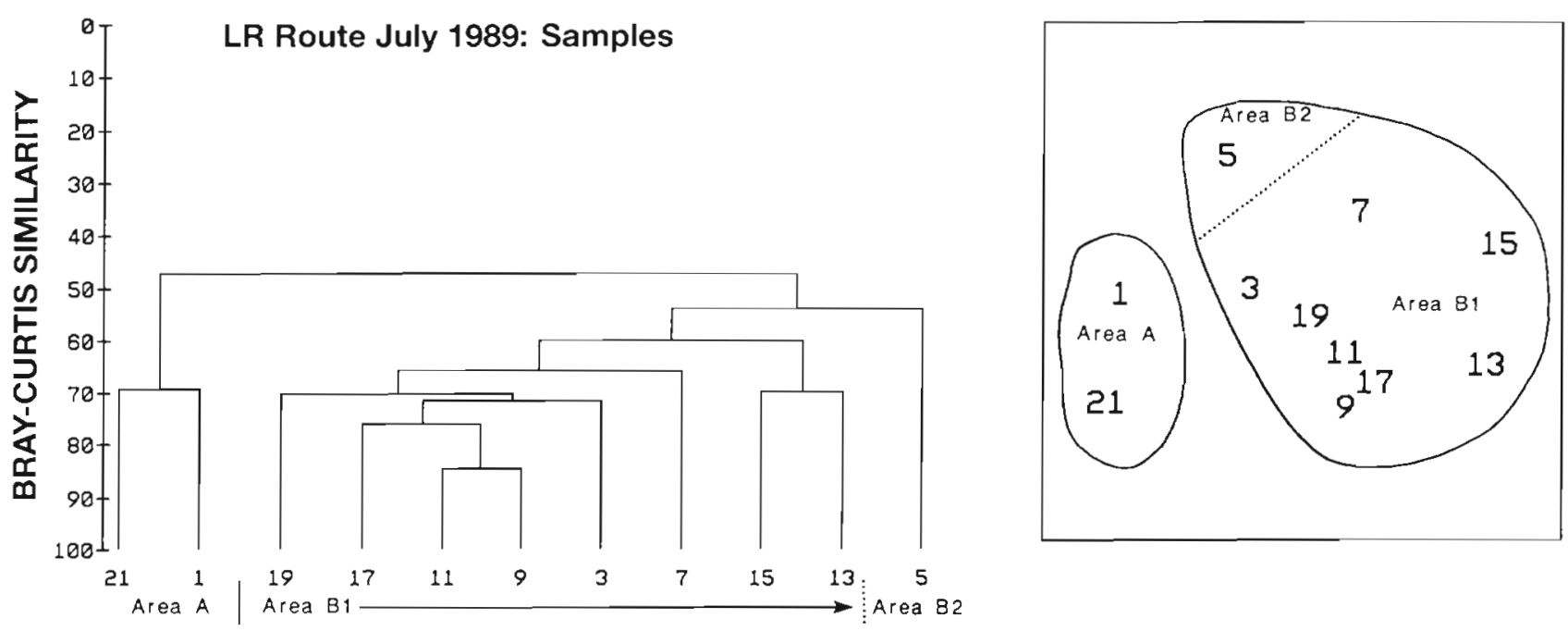

Fig. 7 Grouping of samples on the LR route in July 1989 using the dendrogram (left) resulting from cluster analysis and the scatter plot (right) resulting from MDS analysis 

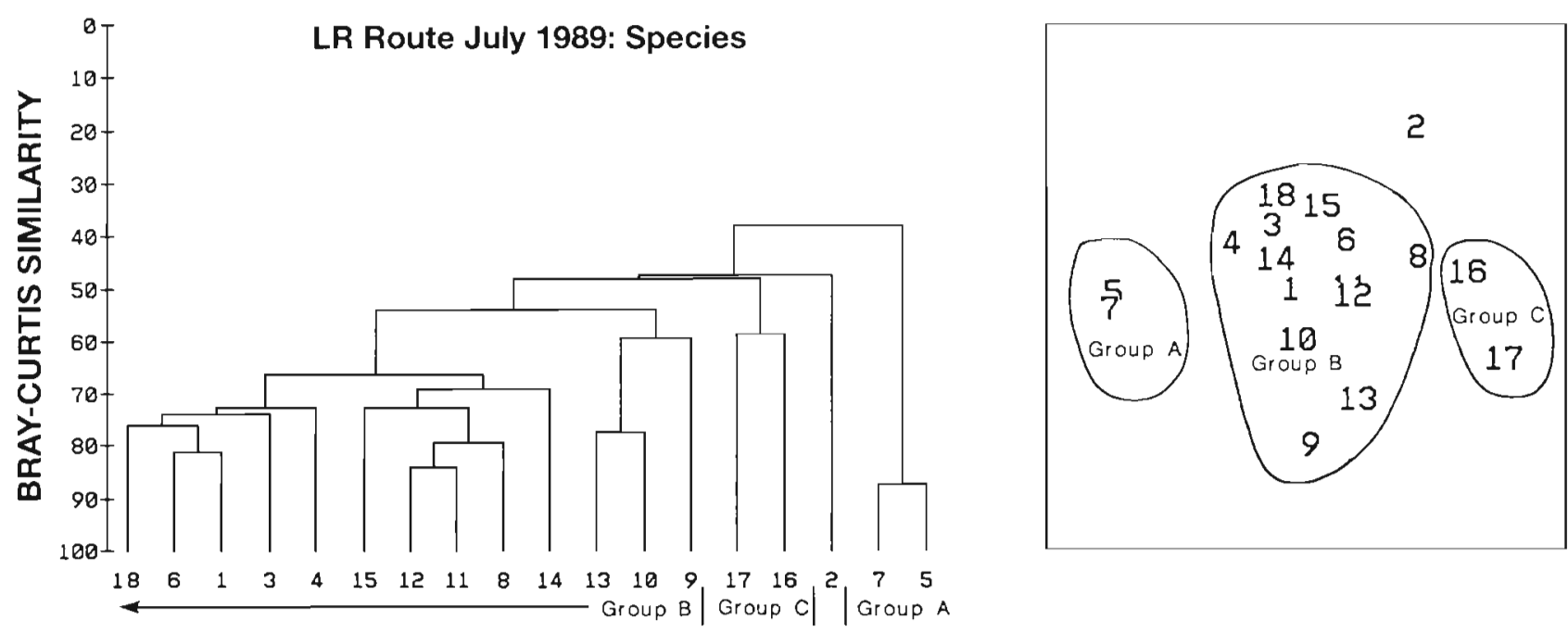

Fig. 8. Grouping of taxa on the LR route in July 1989 using the dendrogram (left) resulting from cluster analysis and the scatter plot (right) resulting from MDS analysis. For key to taxa see Table 1

were most abundant to the west of the front (samples 7 and 9) while the Kattegat was dominated by small copepods and cladocerans. By May the common phytoplankton were dinoflagellates. The samples which were classified as neither Area S nor Area $\mathrm{K}$ in February, March and April contained little plankton. In October and November most diatoms and dinoflagellates were within Group B in the Kattegat.
The results of the analysis of the biota in relation to the environmental variables using the BIO-ENV program are listed in Table 4 . Inevitably there are many cases of high correlation between variables so that it is difficult or impossible to distinguish between their effects using this method (Clarke \& Ainsworth 1993). The irradiance channels are inevitably all highly correlated and on the LD route temperature and salinity

Table 4. The results of BIO-ENV analyses of the weighted correlations between the rank dissimilarites between samples derived from biota identified from CPR records and equivalent values from environmental variables, including data from CPR or UOR dataloggers (Data) on the LR route in 1989 and the LD route in July 1988 and in 1989. The single variable most highly correlated with the biota (best single) and the set of variables which give the highest correlation (best set) and the coefficients are listed

\begin{tabular}{|c|c|c|c|c|c|c|}
\hline Month & Route & Data $^{a}$ & Best single ${ }^{b}$ & Correlation & Best set ${ }^{b}$ & Correlation \\
\hline \multicolumn{7}{|l|}{1988} \\
\hline February & LR & 1 & R1 & 0.408 & R1 & 0.408 \\
\hline April & LR & 4 & Tur & 0.416 & Tur & 0.416 \\
\hline May & LR & 5 & Strat. & 0.309 & Strat, Tur & 0.421 \\
\hline July & LR & 1 & R4 & 0.330 & Ch1, R1, R2, Strat & 0.465 \\
\hline September & LR & 1 & Strat & 0.290 & Tem, Strat & 0.395 \\
\hline October & LR & 2 & Strat & 0.390 & Tem, Strat & 0.434 \\
\hline July & LD & 1 & Tem & 0.547 & D, Tem, Chl, R1 & 0.595 \\
\hline \multicolumn{7}{|l|}{1989} \\
\hline January & $\mathrm{LD}$ & 1 & Tem & 0.387 & Tem, R4 & 0.402 \\
\hline February & $\mathrm{LD}$ & 1 & R1 & 0.259 & R3, R4 & 0.283 \\
\hline March & $\mathrm{LD}$ & 1 & $\mathrm{R} 1$ & 0.415 & D, Tem, Chl, R1 & 0.474 \\
\hline May & LD & 1 & $\mathrm{R} 2$ & 0.406 & Tem, R2 & 0.414 \\
\hline October & $\mathrm{LD}$ & 3 & Sal & 0.481 & D, Sal & 0.540 \\
\hline November & LD & 3 & Sal & 0.535 & $\mathrm{D}$, Tem, Chl & 0.575 \\
\hline
\end{tabular}


MARCH 1989

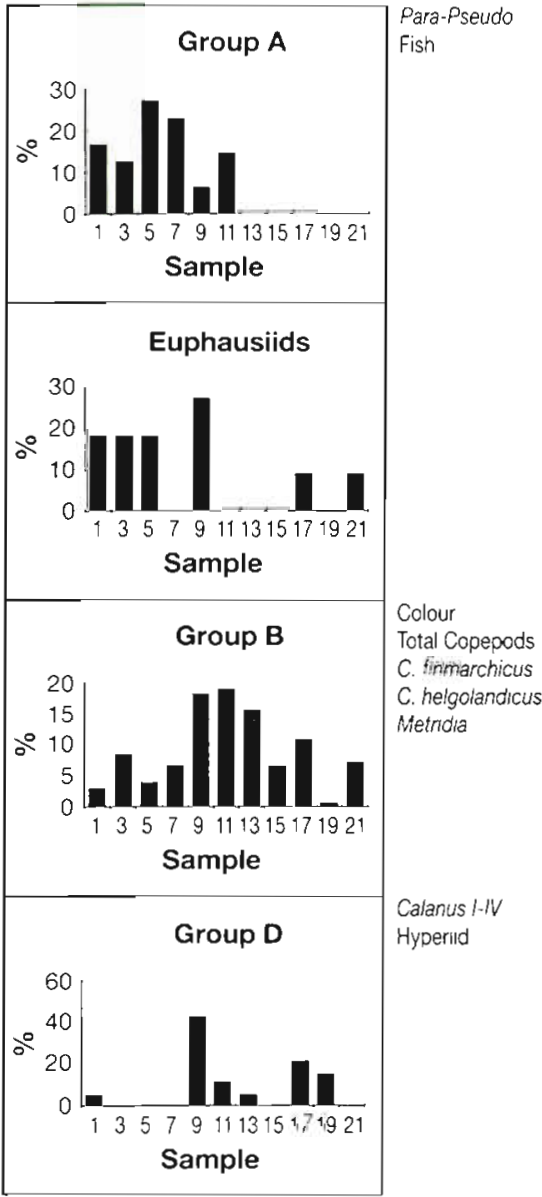

MAY 1989

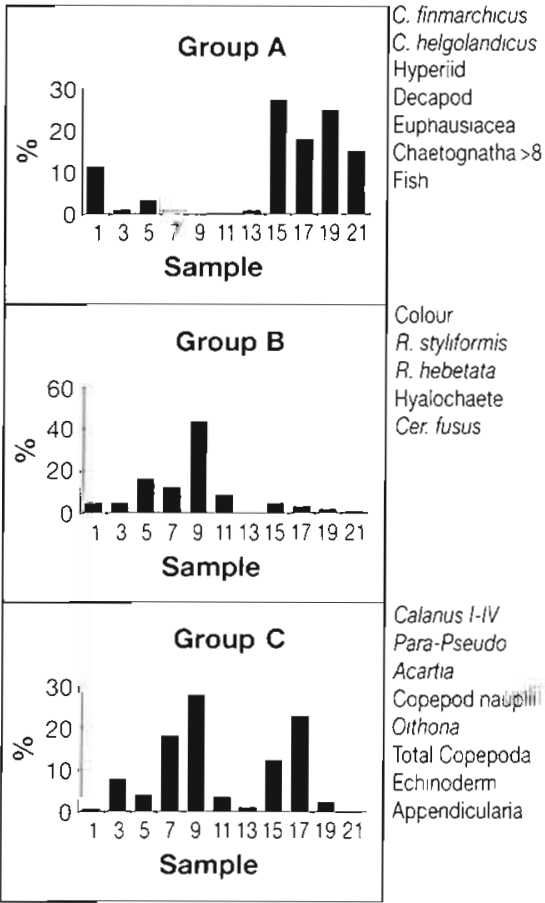

APRIL 1989

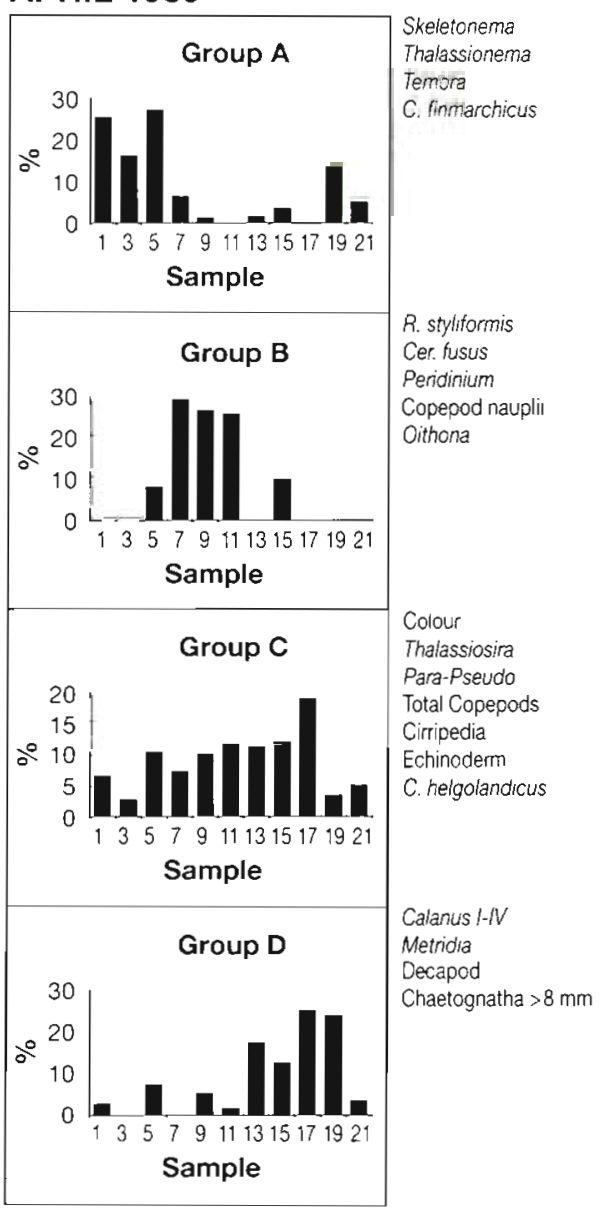

JULY 1989

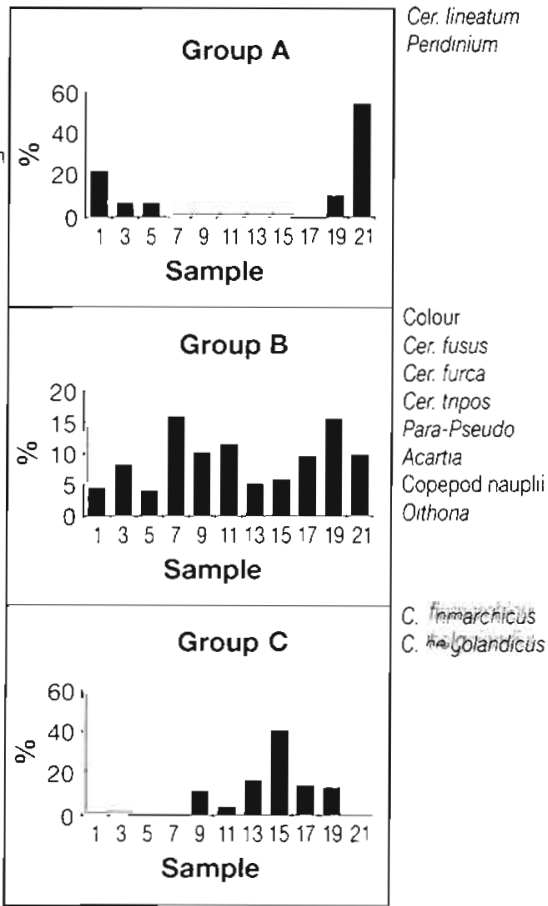

Total Copepods

Evadne

Echinoderm

Appendicularia

Decapod
Fig. 9a. Distribution and composition of groups of planktonic taxa in CPR samples on the LR route in March, April, May and July 1989 

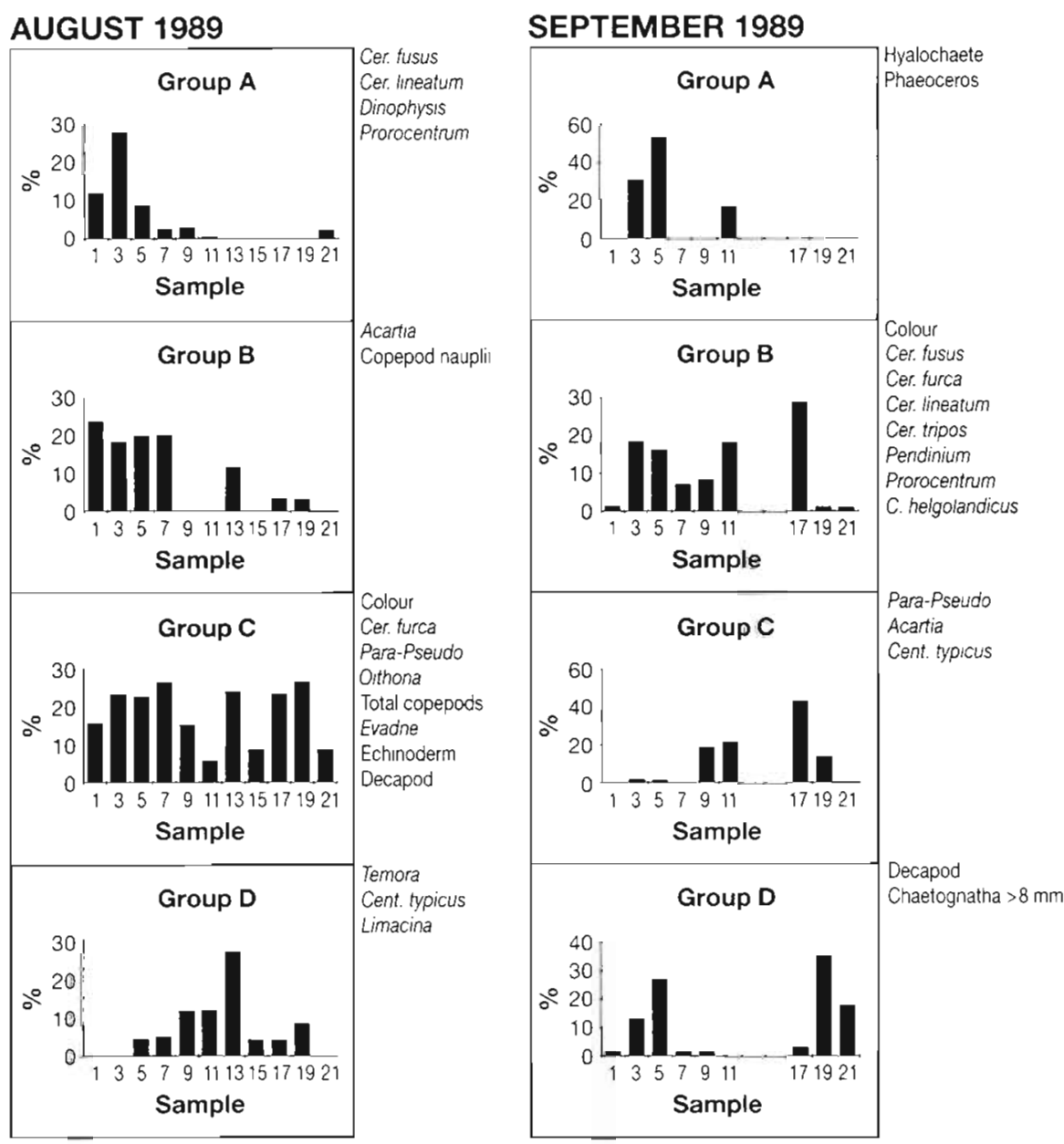

\section{OCTOBER 1989}
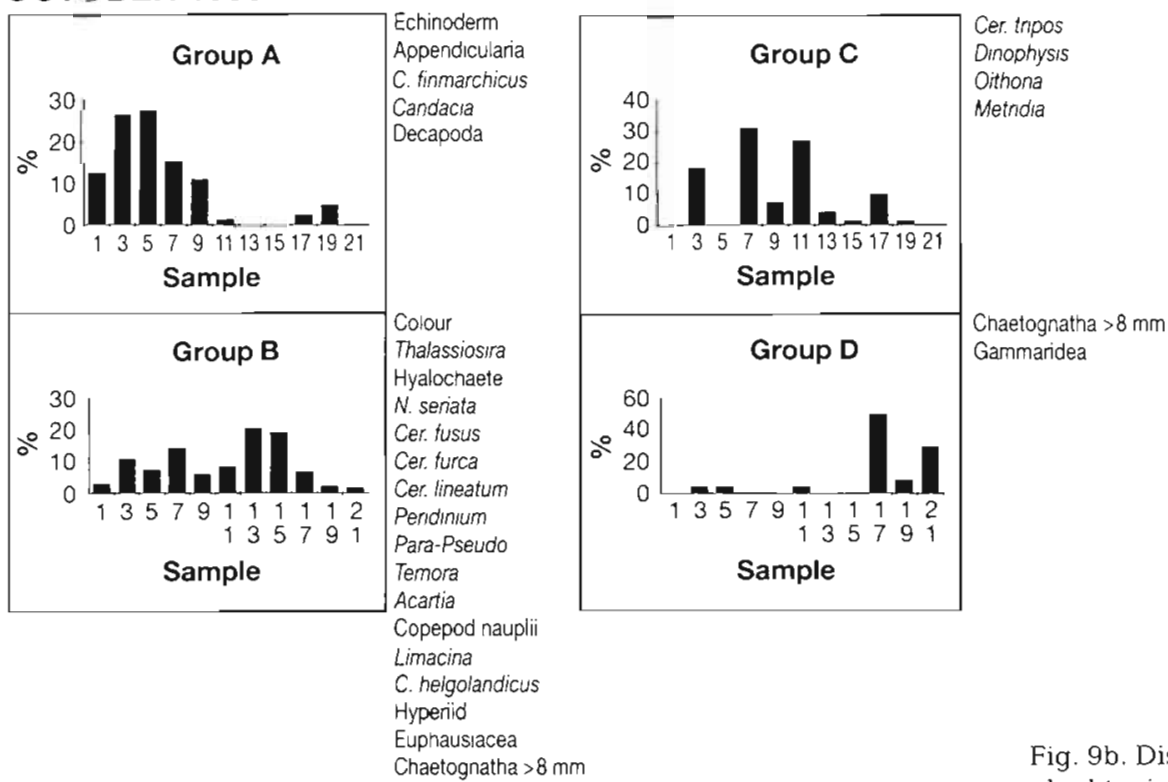

Fig. 9b. Distribution and composition of groups of planktonic taxa in CPR samples on the LR route in August, September and October 1989 


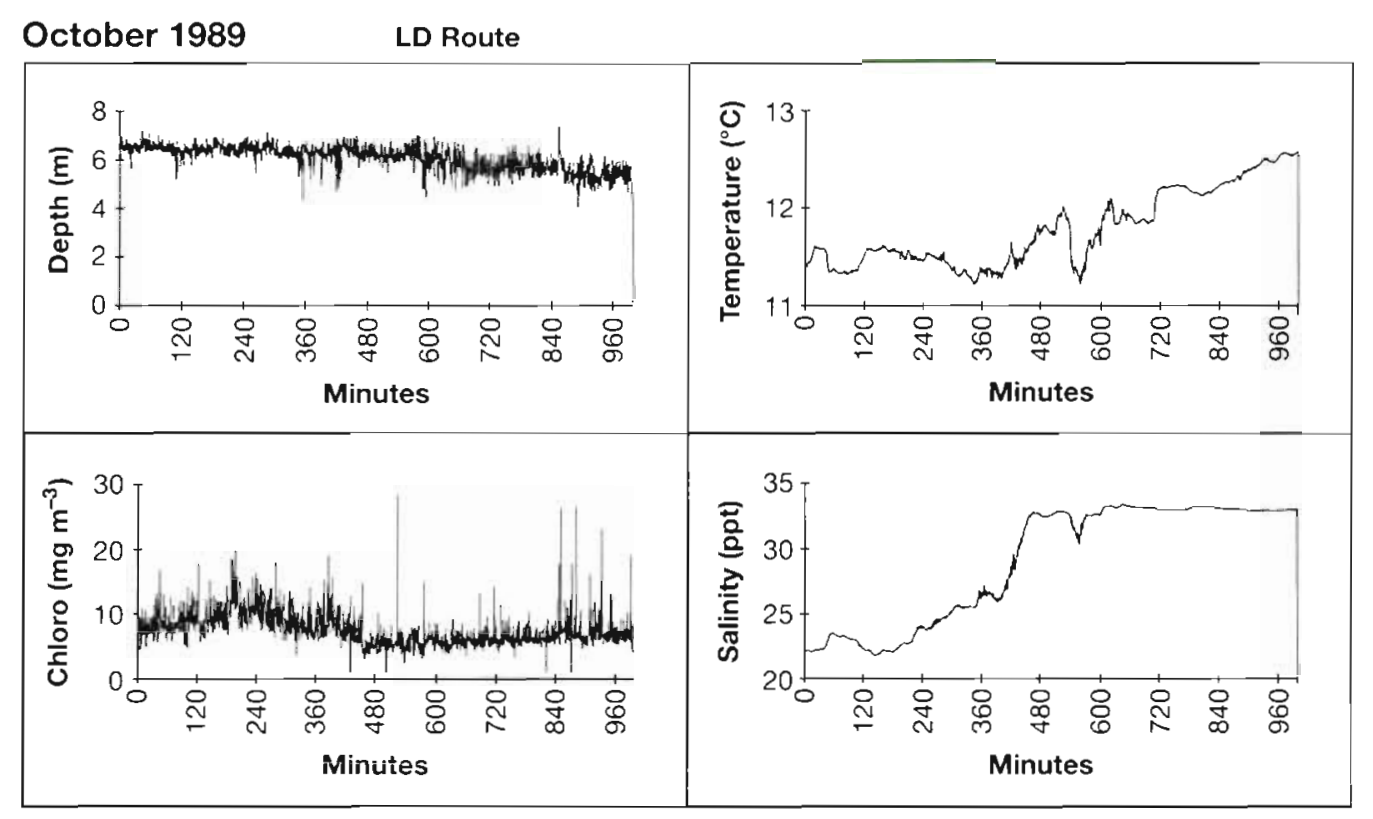

Fig. 10. Results from instrumentation in a CPR towed on the LD route (see Fig. 1) on 27 and 28 October 1989

(where measured) are highly correlated with each other and to the towing depth. The latter varied little, usually by about $1 \mathrm{~m}$ between the minimum and maximum mean depth per CPR plankton sample, but the change was systematic along the route possibly due to change in water density related to the temperature and salinity.

\section{DISCUSSION}

The influence of diel migration on the plankton taken in CPR samples has been recognised and taken into account in processing and interpreting the data throughout the history of the survey (e.g. Hardy 1939; Colebrook et al. 1961) so it is not surprising that the results of the BIO-ENV analyses showed that measures of irradiance were the single variables which best explained the distribution of the biota in 5 of the 14 tows listed in Table 4 and in half the cases such measures were among the best set of variables. The concentration of groups of plankton in samples taken by night was noted on the LR route in February, May, July and August but no comparable groups were found on the LD routes. In May 1989, when samples 1 to 7 of the LD route were taken by day and samples 9 to 17 were taken at night, the group which included adult Calanus finmarchicus, decapod larvae and euphausiids showed no concentration in the night samples but the division between day and night approximated to the position of the front between Skagerrak water and Kattegat water. In February the LD tow was mostly taken at night and in March samples 1 and 3 were taken by day and plankton was sparse in these samples so the relationship with light does not seem to be a major factor on this route. Diel vertical migration of zooplankton is very variable. Williams \& Lindley (1982) found differences between the beginning and end of May in the diel distributions of Calanus finmarchicus copepodites and unpublished data on Pagurus bernhardus zoeas show that these may remain in near surface waters, migrate through a thermocline or remain beneath a thermocline according to conditions. Such variability could contribute to the fact that measures of irradiance were not always among the environmental factors significantly influencing the plankton distributions in the single depth CPR tows. Integrated depth samples would give more accurate data on the total abundance and composition of the plankton, particularly in stratified waters, but would merge vertically partitioned assemblages.

On the LR route, the value of the stratification parameter was the best single variable for explaining the biotic variability in 3 months and in each of these it was included in the 'best set'. In April, turbidity was the best single variable. In the depth range sampled by the UOR on this route turbidity is usually much higher in the permanently mixed water to the south of the Flamborough front than in the stratified water to the North (see Fig. 4). The grouping of samples at or near to the southern end of the route with one or more of the most northerly samples, as in May, July and October (Table 2) probably reflects the transitional (Pingree \& Griffiths 1978) nature of the water as defined by the 
Fig. 11. Temperature $\left({ }^{\circ} \mathrm{C}\right)$ recorded during instrumented CPR tows on the LD route (see Fig. 1) in July 1988 and during 1989. Left: original data; right: mean values per analysed plankton sample (for positions see Fig. 12). Arrows indicate the position of the front between Baltic water (low salinity) and North Sea water
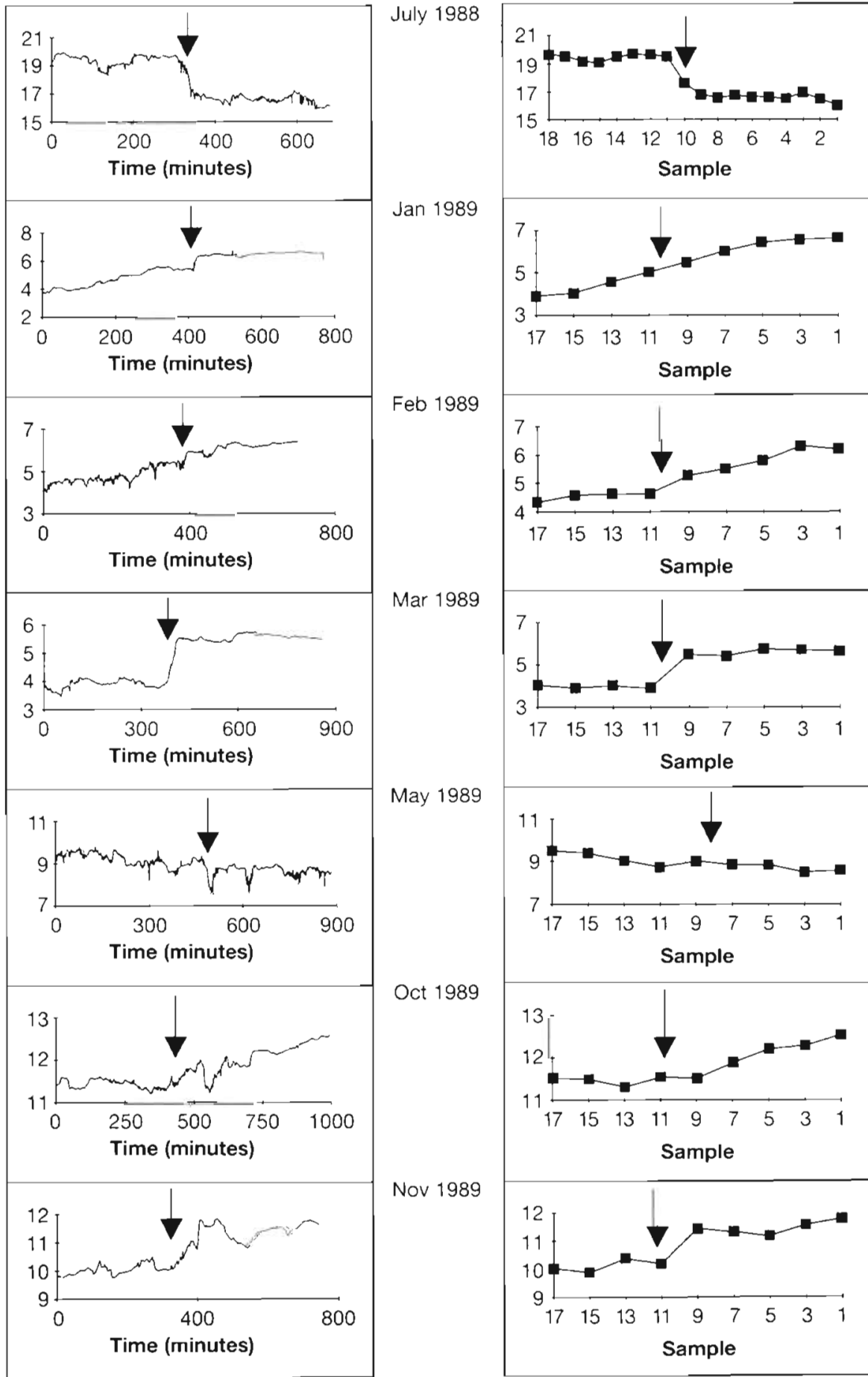

stratification parameter. The plots in Fig. 2 show weaker stratification at the northern end of the route than in the central part of the tows in June and no stratification in the northern end in September.

On the LD route, the correlations from the BIO-ENV analyses were generally higher than on the LR route. This can be related to the strong permanent front and the associated contrasts in the environmental parameters. Salinity was the most important factor in the 2 months when this was measured (October and November) and as salinity, temperature and towing depth were highly correlated it seems that it is not possible to regard these as independent in these analyses. 


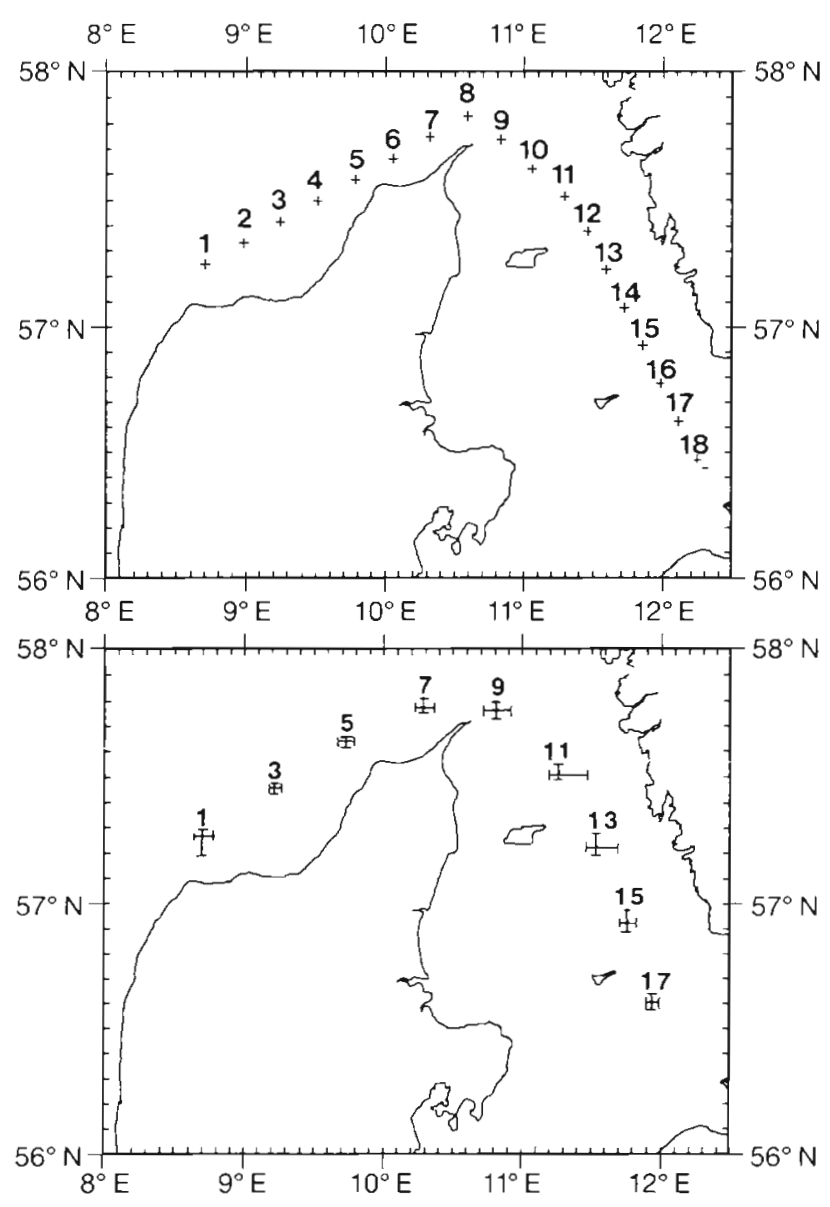

Fig. 12. Distribution of analysed plankton samples on the LD route in July 1988 (upper) and during 1989 (lower). In the lower chart the bars giving the range of latitude and longitude of the mid-points of the samples intersect at the mean position
The best correlations from the BIO-ENV analyses presented here are lower than the examples from benthic surveys presented by Clarke \& Ainsworth (1993). It is possible that environmental variables which were not measured in the present study, such as nutrients or toxins, might have played a significant role in influencing the plankton. Nutrient availability in the photic zone of the open sea is related to stratification (e.g. Cushing 1989). Alternatively the dynamic nature of plankton distributions may limit detection of response by plankton to local environmental effects (Warwick 1993). The method may be more appropriately applied to plankton surveys over a 2-dimensional array of stations over a restricted area (e.g. Collins \& Williams 1982, Siokuo-Frangou \& Papathanassiou 1991) than the long (approx. $300 \mathrm{~km}$ ) 'transects' of the CPR tows. A limitation to the interpretation of such surveys in the open sea is the 'white noise'-like character of plankton distributions described by Tsuda et al. (1993) which led those authors to conclude that quantitative sampling required samples taken over $>5 \mathrm{~km}$, a requirement that the $16 \mathrm{~km}$ CPR samples fulfil.

The variability of the composition of the assemblages identified from the analyses of the data varied through the year can be attributed to the effects of advection and the dynamics of the taxa within areas of different hydrographic characteristics. An example of advection is the occurrence of Candacia armata in Group A on the LR route in October 1989. This species is associated with inflow of water into the North Sea from the north (e.g. Rae \& Rees 1947). The changes in abundance and distributions of the diatoms and dinoflagellates generally conform to the pattern of succession related to stratification and con-
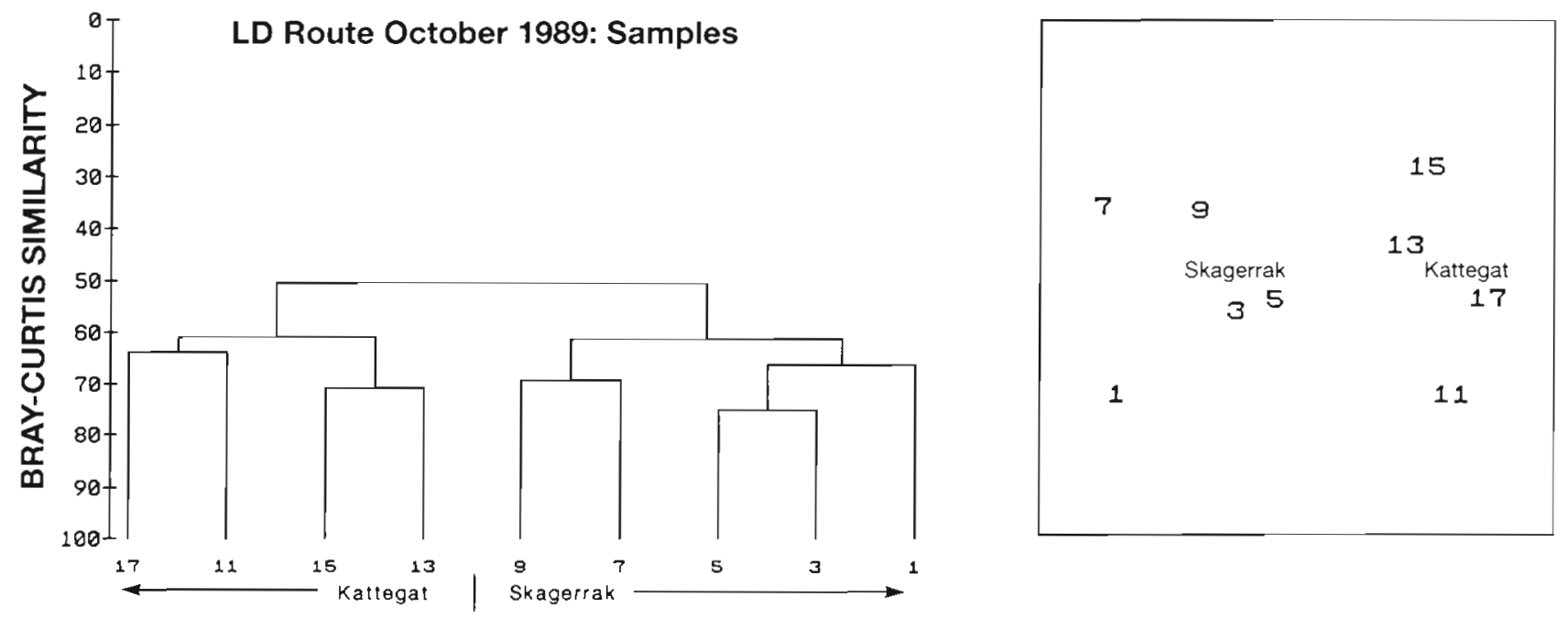

Fig. 13. Grouping of samples on the LD route in October 1989 using the dendrogram (left) resulting from cluster analysis and the scatter plot (right) resulting from MDS analysis 

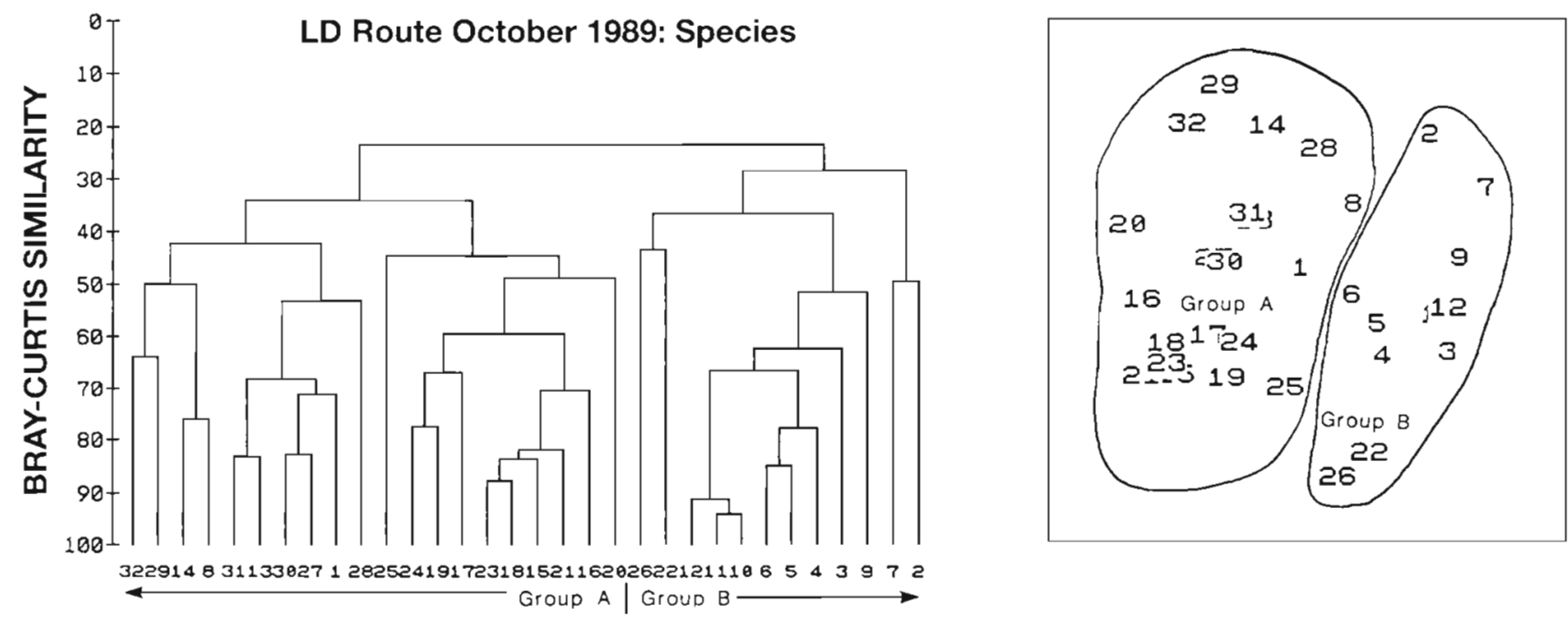

Fig. 14. Grouping of taxa on the LD route in October 1989 using the dendrogram (left) resulting from cluster analysis and the scatter plot (right) resulting from MDS analysis. For key to taxa see Table 1

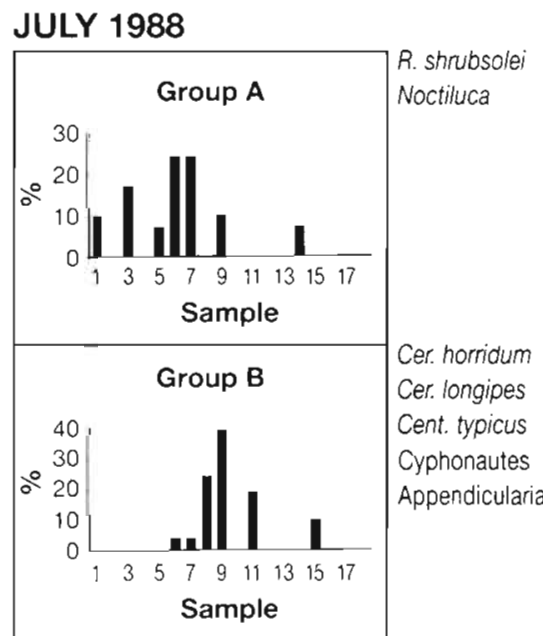

\section{JANUARY 1989}

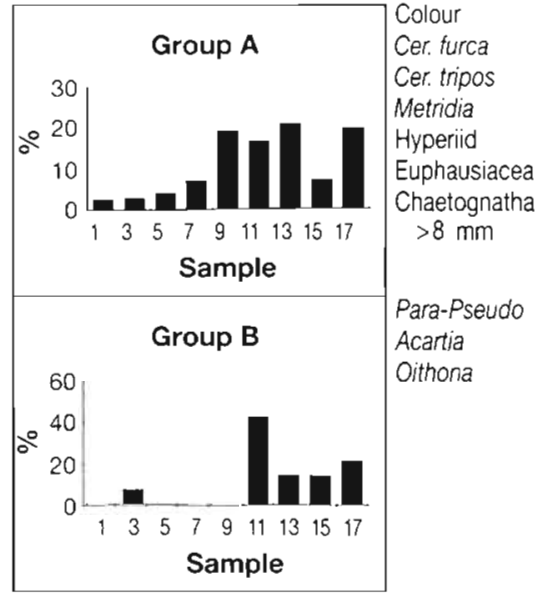

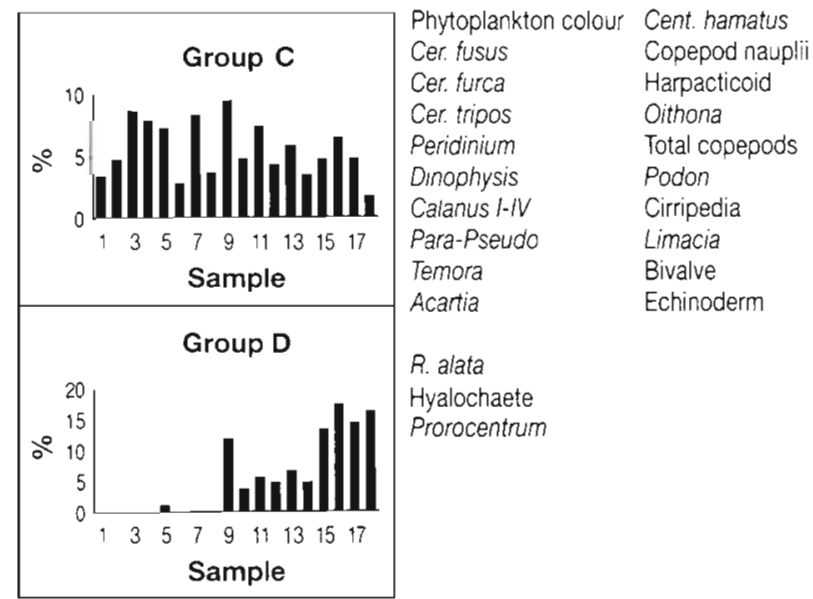

FEBRUARY 1989

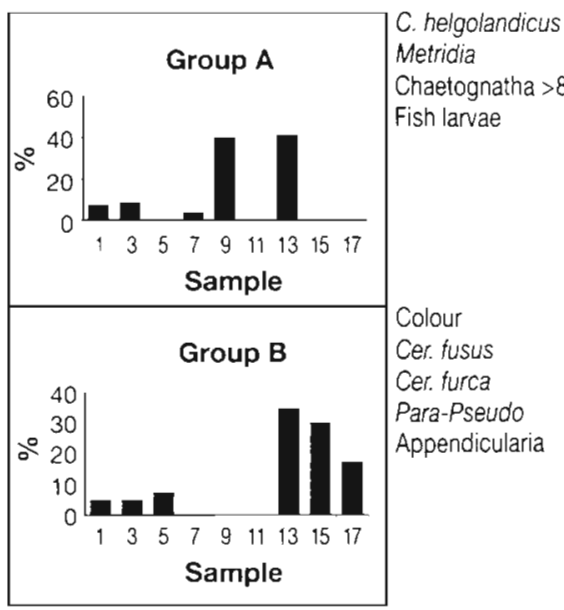

Fig. 15a. Distribution and composition of groups of planktonic taxa in CPR samples on the LD route in July 1988 and January and February 1989 
MARCH 1989

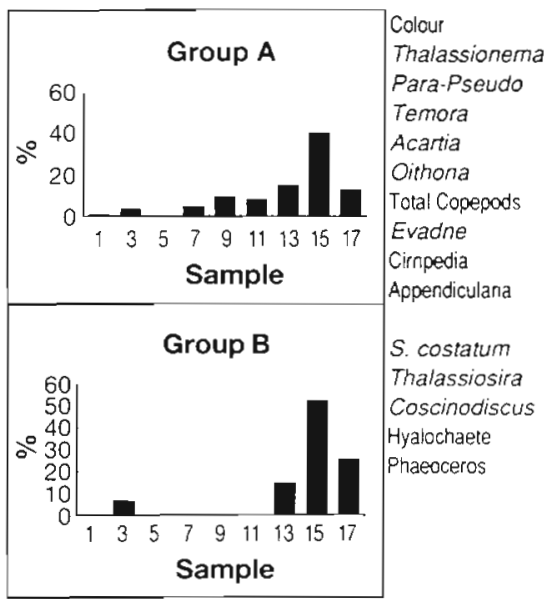

MAY 1989

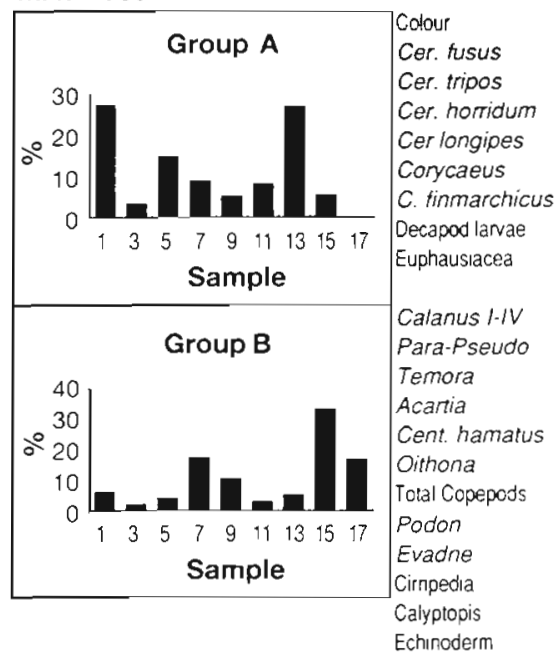

NOVEMBER 1989

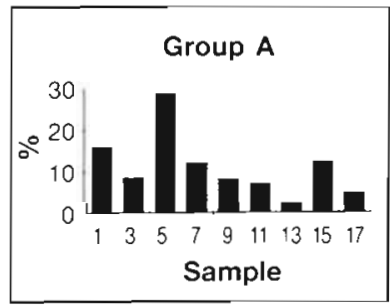

APRIL 1989

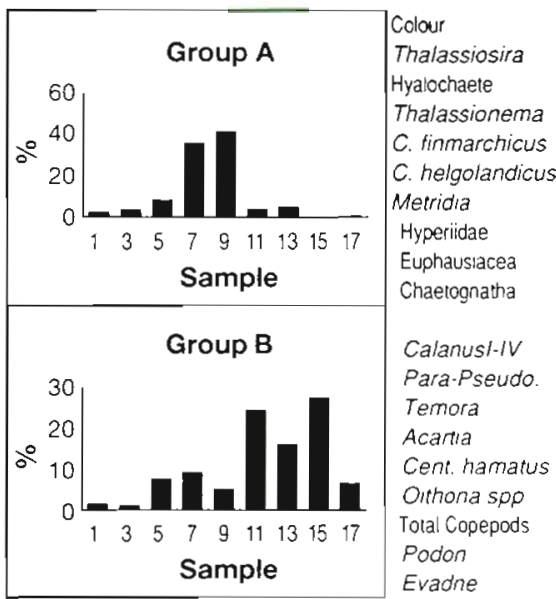

\section{OCTOBER 1989}

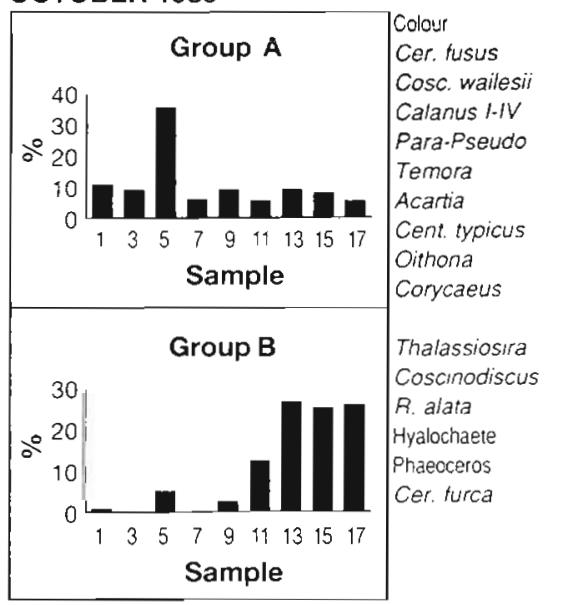

Tot Cops

Limacina

Bivaive

Echinoderm

C. helgolandicus

Candacia

Mysid

Hypenid

Decapod

Chaetognatha $>8 \mathrm{~mm}$

Cer, lineatum

Cer. tripos

Dinophysis

Evadne

C. finmarchicus

Fig. 15b. Distribution and composition of groups of planktonic taxa in CPR samples on the LR route in March, April, May, October and November 1989

sequent nutrient availability in temperate waters as discussed by Cushing (1989).

The environmental data collected by the instrumented CPRs and the UORs made it possible to identify the positions of the fronts defining the boundaries of water masses. This direct evidence reinforced what would otherwise have been only inferences drawn from interpretation of the plankton data. The data from the UOR on the LR route defined the position of the
Flamborough front in relation to the single depth data record of the CPR and supported the definition of the frontal position from the CPR data. The comparison of the graphs of mean temperature data for each plankton sample with those of the full data set justify the logging the data at high frequency to identify the positions of the fronts.

Aspects of the results of the CPR survey in the North Sea in 1989 were exceptional. Ceratium spp. and sev- 
eral zooplankton taxa were unusually abundant (Dickson et al. 1993, CPR survey team 1993), the seasonal cycles of Ceratium spp. and most decapod larvae were atypically early (Dickson et al. 1993, Lindley et al. 1993) and doliolids were recorded in the eastern North Sea for the first time since 1911 (Lindley et al. 1990). These events and more general interannual changes in the plankton (Colebrook 1991) have been attributed to climatic variation including high winter temperatures (Lindley et al. 1993) and anomalous wind patterns (Dickson et al. 1993). The long-term time series of the CPR survey have made it possible to quantify these changes in the plankton but comparable detailed hydrographic data to link climatic cause to ecological effect are absent. Instruments such as the instrumented CPR and the UOR towed by ships-of-opportunity combined with remote sensing by satellite (e.g. Aiken 1989) provide the potential for such long-term monitoring of hydrographic variables. In view of the known importance of stratification in the dynamics of plankton in temperate waters (Sverdrup 1953, Craig 1960, Robinson 1970, Cushing 1989) undulating vehicles, like the UOR, which allow direct observation of vertical structure on a fine scale would be the preferred option for deployment from ships-ofopportunity.

Acknowledgements. The CPRs and UORs were towed on the LR route by the MV 'Astrea' (NORCARGO Ltd.) and on the LD route by MV 'Dana Hafnia' and MV 'Dana Futura' (DFFS). We thank the owners, agents, masters and crews for their willing co-operation. We acknowledge all personnel involved with the development of the instrumented vehicles at PML (R. H. Bruce, C. D. Barrett, I. E. Bellan and N. J. Bloomer). During 1988 and 1989 the data loggers were prepared for deployment and the results processed by Mr N. C. Halliday. Instrumentation of CPRs was financed by the UK Department of the Environment (DoE) (contract 7/8/121) and the provision of UORs and their deployment was financed by the UK Ministry of Agriculture, Fisheries And Food (MAFF) (contract DHA10(GCB10)). The analysis of the CPR samples was carried out by the survey team and at the time of these studies the survey was supported by MAFF and DoE as part of PML programmes. The work comprised part of PML Laboratory Project 3, Community Ecology.

\section{LITERATURE CITED}

Aiken, J. (1980). A marine environmental recorder. Mar. Biol. 57: $237-240$

Aiken, J. (1981a). The Undulating Oceanographic Recorder Mark 2. J. Plankton Res. 3: 551-560

Aiken, J. (1981b). A chlorophyll sensor for automatic, remote, operation in the marine environment. Mar. Ecol. Prog. Ser. 4: $235-239$

Aiken, J. (ed.) (1989). The North Sea: satellite colour atlas. Cont. Shelf Res. 9: 665-765

Aiken, J., Bellan, I. (1986). A simple hemispherical logarith- mic light sensor. SPIE 637, Ocean Optics VIII: 211-216

Andersson, L., Rydberg, L. (1993). Exchange of water and nutrients between the Skagerrak and the Kattegat. Estuar. coast. Shelf Sci. 36: 159-181

Clarke, K. R., Ainsworth, M. (1993). A method of linking multivariate community structure to environmental variables. Mar. Ecol. Prog. Ser. 92: 205-219

Colebrook, J. M. (1960). Continuous plankton records: methods of analysis, 1950-59. Bull mar. Ecol. 6: 51-64

Colebrook, J. M. (1964). Continuous plankton records: a principal component analysis of the geographical distribution of zooplankton. Bull. mar. Ecol. 6: 78-100

Colebrook, J. M. (1972). Variability in the distribution and abundance of the plankton. Spec. Publ. int. commn. NW Atlant. Fish. 8: 167-186

Colebrook, J. M. (1984). Continuous plankton records: relationships between species of phytoplankton and zooplankton in the seasonal cycle. Mar. Biol. 83: 313-323

Colebrook, J. M. (1991). Continuous plankton records: from seasons to decades in the plankton of the north-east Atlantic. In: Kawaski, T., Tanaka, S., Toba, Y., Taniguchi, A. (eds.) Long-term variability of pelagic fish populations and their environment. Pergamon Press, Oxford, p. 20-45

Colebrook, J. M., Glover, R. S., Robinson, G. A. (1961). Continuous plankton records 1948-1956: contributions towards a plankton atlas of the north-eastern Atlantic and the North Sea. Bull. mar. Ecol. 5: 67-80

Colebrook, J. M., Warner, A. J, Proctor, C. A., Hunt, H. G., Pritchard, P., Joyce, D., Barnard, R. (1991). 60 years of the Continuous Plankton Recorder Survey: a celebration. The Sir Alister Hardy Foundation for Ocean Science, Plymouth

Collins, N. R., Williams, R. (1982). Zooplankton communities in the Bristol Channel and Severn Estuary. Mar. Ecol. Prog. Ser. 9: 1-11

CPR survey team (1993). Continuous plankton records: the North Sea in the 1980s. ICES mar. Sci. Symp. 195: 243-248

Craig, R. E. (1960). A note on the dependence of catches on temperature and wind in the Buchan pre-spawning herring fishery. J. Cons. int. Explor. Mer 25: 185-208

Cushing, D. H. (1989). A difference in structure between ecosystems in strongly stratified waters and in those that are only weakly stratified. J. Plankton Res. 11: 1-13

Dickson, R. R., Colebrook, J. M., Svendsen, E. (1993). Recent changes in the summer plankton of the North Sea. ICES mar. Sci. Symp. 195: 232-242

Edinburgh Oceanographic Laboratory (1973). Continuous plankton records 1948-1956: a plankton atlas of the north Atlantic and the North Sea. Bull. mar. Ecol. 7: 1-174

Field, J. G., Clarke, K. R., Warwick, R. M. (1982). A practical strategy for analysing multi-species distribution patterns. Mar. Ecol. Prog. Ser. 8: 37-52

Hardy, A. C. (1939). Ecological surveys with the continuous plankton recorder: object, plan and methods. Hull. Bull. mar. Ecol. 1: 1-57

Hays, G. C., Warner, A. J. (1993). Consistency of tow speed and sampling depth for the continuous plankton recorder. J. mar. biol. Ass. U.K. 73: 967-970

Lindley, J. A., Roskell, J., Warner, A. J, Halliday, N. C., Hunt, H. G., John, A. W. G., Jonas, T. D. (1990). Doliolids in the German Bight in 1989: evidence for exceptional inflow into the North Sea. J. mar. biol. Ass. U.K. 70:679-682

Lindley, J. A., Williams, R., Hunt, H. G. (1993). Anomalous seasonal cycles of decapod crustacean larvae in an exceptionally warm year. J. exp. mar. Biol. Ecol. 172: 47-65

Lucas, C. E. (1942). Continuous plankton records: phytoplankton in the North Sea 1938-1939. Part II - Dinoflagellates. Hull Bull. mar. Ecol. 2: 19-46 
Pattiaratchi, C. B., Micallef, S., Aiken, J., Osbourne, M. J., Collins, M. B., Williams, R. (1989). Chlorophyll variability at Ocean Weather Station Lima $\left(57^{\circ} \mathrm{N}, 20^{\circ} \mathrm{W}\right)$. In: Ryland, J. S., Tyler, P. A. (eds.) Reproduction, genetics and distributions of marine organisms. Olsen \& Olsen, Fredensborg, p. $423-429$

Pingree, R. D., Griffiths, D. K. (1978). Tidal fronts on the shelf seas around the British Isles. J. geophys. Res. 83 $4615-4622$

Rae, K. M. (1952). Continuous plankton records: explanation and methods, 1946-1949. Hull Bull. mar. Ecol. 3: 135-155

Rae, K. M., Rees, C. B. (1947). Continuous plankton records: the copepoda of the North Sea 1938-1939. Hull Bull. mar. Ecol. 2: 95-133

Reid, P. C., Hunt, H. G., Jonas, T D. (1983). Exceptional blooms of diatoms associated with anomalous hydrographic conditions in the Southern Bight in early 1977. J. Plankton Res. 5: 755-765

Richardson, K. (1985). Plankton distribution and activity in the North Sea/ Skagerrak-Kattegat frontal area in April 1984. Mar. Ecol. Prog. Ser. 26: 233-244

Robinson, G. A. (1961). Contribution towards a plankton atlas of the north-eastern Atiantic and the North Sea. Part I: Phytoplankton. Bull. mar. Ecol. 5: 81-89

Robinson, G. A. (1965). Contribution towards a plankton atlas of the north Atlantic and the North Sea. Part IX: Phytoplankton. Bull. mar. Ecol. 6: 81-89

Robinson, G. A. (1968). Distribution of Gonyaulax tamarense Lebour in the western North Sea in April, May and June 1968. Nature 220: 22-23

Robinson, G. A. (1970). Continuous plankton records: variation in the seasonal cycle of phytoplankton in the north Atlantic. Bull. mar. Ecol. 6, 333-345

Robinson, G. A., Aiken, J., Hunt, H. G. (1986). Synoptic sur-

This article was submitted to the editor veys of the western English Channel. The relationship between plankton an hydrography. J. mar. biol. Ass. U.K. 66: $201-218$

Siokou-Frangou, I., Papathanassiou, E. (1991). Differentiation of zooplankton populations in a polluted area. Mar. Ecol. Prog. Ser. 76: 41-51

Sverdrup, H. U. (1953). On conditions for the vernal blooming of the phytoplankton. J. Cons. int. Explor. Mer 18: 287-295

Tsuda, A., Sugisaki, H., Ishimaru, T., Saino, T., Sato, T. (1993). White-noise like distribution of the oceanic copepod Neocalanus cristatus in the sub-arctic North Pacific. Mar. Ecol. Prog. Ser. 97: 39-46

Warwick, R. M. (1993). Environmental impact studies on marine communities: pragmatical considerations. Aust. J. Ecol. 18: 63-80

Williams, R., Aiken, J. (1990). Optical measurements from underwater towed vehicles deployed from ships of opportunity in the North Sea. In: Nielson, H. O. (ed.) Environment and pollution measurement sensors and systems. SPIE 1269: 186-194

Williams, R., Lindley, J. A. (1982). Plankton of the Fladen Ground during FLEX 76. III. Vertical distribution, population dynamics and production of Calanus finmarchicus (Crustaced: Copepoda). Mar. Biol. 60:47-56

Williams, R., Lindley, J. A. (in press). Strategy and application of sampling large marine ecosystem with the Continuous Plankton Recorder (CPR) and Undulating Oceanographic Recorder (UOR)/Aquashuttle. In: Okemwa, E. N (ed.) Proceedings of status and future of large marine ecosystems (LME) of the Indian Ocean, Mombasa, Kenya, 28 March 2 April 1993

Williams, R., Lindley, J. A., Hunt, H. G., Collins, N. R. (1993). Plankton community structure and geographical distribution in the North Sea. J. exp. mar. Biol. Ecol. 172: 143-156

Manuscript first received: September 15, 1993

Revised version accepted: February 15, 1994 